\title{
Graphene Composites for Lead Ions Removal from Aqueous Solutions
}

\author{
Mukesh Kumar ${ }^{1, *}$, Jin Suk Chung ${ }^{2}$ and Seung Hyun Hur ${ }^{2, *}$ \\ 1 Department of Chemistry, Sri Aurobindo College, University of Delhi, Delhi-110017, India \\ 2 School of Chemical Engineering, University of Ulsan, Daehakro 93, Namgu, Ulsan 680-749, Korea \\ * Correspondence: mknanocomposites@gmail.com (M.K.); shhur@ulsan.ac.kr (S.H.H.)
}

Received: 3 June 2019; Accepted: 15 July 2019; Published: 22 July 2019

\begin{abstract}
The indiscriminate disposal of non-biodegradable, heavy metal ionic pollutants from various sources, such as refineries, pulp industries, lead batteries, dyes, and other industrial effluents, into the aquatic environment is highly dangerous to the human health as well as to the environment. Among other heavy metals, lead ( $\mathrm{Pb}(\mathrm{II}))$ ions are some of the most toxic pollutants generated from both anthropogenic and natural sources in very large amounts. Adsorption is the simplest, efficient and economic water decontamination technology. Hence, nanoadsorbents are a major focus of current research for the effective and selective removal of $\mathrm{Pb}(\mathrm{II})$ metal ions from aqueous solution. Nanoadsorbents based on graphene and its derivatives play a major role in the effective removal of toxic $\mathrm{Pb}(\mathrm{II})$ metal ions. This paper summarizes the applicability of graphene and functionalized graphene-based composite materials as $\mathrm{Pb}$ (II) ions adsorbent from aqueous solutions. In addition, the synthetic routes, adsorption process, conditions, as well as kinetic studies have been reviewed.
\end{abstract}

Keywords: graphene oxide; nanoadsorbents; lead adsorption; graphene functionalization; composite; magnetite; removal efficiency

\section{Highlights}

- Contaminated waste water is one of the most serious risks for living organisms as well as to the environment.

- Nanotechnology offers best expectations over traditional technologies for wastewater treatment.

- Adsorption technology is the phenomenon of adhesion of solid substances onto the surface of adsorbent.

- Graphene-based nanoadsorbents exhibited a great potential towards effective removal of lead ions from aqueous solution.

- Graphene preparation, characterization, and applications of graphic-based composites for the removal of lead ions from aqueous solution have been discussed.

\section{Background}

Water decontamination is one of the most serious challenges among scientists globally due to the increasing population, pollution, and global warming [1-5]. Wastewater from developing industries, such as chemical manufacturing, metallurgical, battery manufacturing, papermaking, and mining industries produce a very large amount of various toxic pollutants in the form of heavy metal ions [6-9]. Excess heavy metal ions concentration in wastewater is a serious risk to public health as well as to other living organisms on Earth [10-12]. These toxic heavy metal pollutants are widely found in the Earth's crust which tends to bioaccumulate in living organisms; they are non-biodegradable, which can cause various diseases, genetic disorders, and lethal ecological effects [12-15]. Heavy metal ions in aqueous media pose several toxic threats to the human health as well as to the other living organisms even at low 
concentrations. As per the regulatory system of the WHO (World Health Organization), the permissible concentration of $\mathrm{Pb}$ (II) (Lead (II)) in wastewater is approximately $0.01 \mathrm{mg} / \mathrm{L}$ [16-18]. Moreover, the excess exposure of $\mathrm{Pb}$ (II) can lead to irreversible brain damage, cardiovascular disease, cognitive impairment, encephalopathy disease symptoms and even death [19-22]. $\mathrm{Pb}$ (II) is also extremely toxic to the nervous system, kidneys, and may lead to a wide range of human health issues such as nausea, anemia, infertility, coma, convulsions, hemochromatosis, renal failure, cancer, adverse effects on the metabolism and intelligence, and dermatitis brass chills, and cramps in the calves [12,14,23-27].

The current tight regulatory systems do not allow the release of heavy metal ions-contaminated wastewaters into the environment and require the removal of all toxic pollutants before discharging. Therefore, the development of efficient and economical novel materials and technologies for the effective removal of metal ion pollutants are required. Several traditional techniques have been used for the removal of heavy metal ions from aqueous medium, including reverse osmosis, precipitation, biosorption, ion-exchange, electrochemical processes, membrane filtration, irradiation, coagulation, and adsorption [28-40]. Table 1 lists the techniques used for $\mathrm{Pb}$ (II) ions removal from the wastewaters. The main disadvantages of conventional techniques include high cost, metallic sludge generation, incomplete removal, and disposal of secondary waste. Therefore, a cost effective, potential and convenient decontamination technology for wastewater treatment is highly desirable. The high efficiency, cost-effective, and simple operation makes adsorption technology one of the most promising technology for the effective removal of the heavy metal ions from the aqueous solution which adsorb metallic ions at solid-liquid interfaces [41-49]. On the other hand, adsorption technology has several challenges, such as selective recovery and reuse of valuable adsorbents and pollutants in the presence of humic substances [50,51]. Adsorbents developed with favorable structures, morphologies, superior adsorption capacities, and ease of separation are a major focus of the current research [26,52-60]. Recently, the development of nanotechnology has attracted considerable attention due to the remarkable potential of the nanoadsorbents for the selective and effective removal of ionic pollutants from aqueous solution when compared with the traditional adsorbents $[13,33,61-66]$. The nanoadsorbents play a major role in the separation of heavy metal ions because they are effective sorbents due to their unique structural properties and specific adsorption tendency. Nanoadsorbents have several unique advantages over conventional adsorbents due to their large specific surface area to volume ratio, tunable pore size, regeneration, reusability etc. [33,56,67-71].

Table 1. Techniques characteristics used for $\mathrm{Pb}(\mathrm{II})$ removal.

\begin{tabular}{|c|c|c|c|c|}
\hline Techniques & Materials used & Advantages & Disadvantages & Ref. \\
\hline Solvent Extraction & $\begin{array}{l}\text { Extractants, such as sodium } \\
\text { succinate, lauryl ammonium } \\
\text { compounds etc. }\end{array}$ & $\begin{array}{l}\text { Efficient at higher } \\
\text { concentration, better recovery } \\
\text { of metals etc. }\end{array}$ & $\begin{array}{l}\text { Complex, require continuous } \\
\text { energy consumption, need } \\
\text { chemicals, inappropriate } \\
\text { efficiency etc. }\end{array}$ & {$[74,75]$} \\
\hline Ion Exchange & $\begin{array}{l}\text { Organic-inorganic or hybrid ion } \\
\text { exchanger as }-\mathrm{SO}_{3} \mathrm{H} \text { and } \\
\text {-COOH based resin, } \\
\text { salicylic-melamine-formaldehyde } \\
\text { resin etc. }\end{array}$ & $\begin{array}{l}\text { Simple operation, high } \\
\text { treatment capacity, high } \\
\text { efficiency, fast kinetics, able to } \\
\text { clean up to ppb level etc. }\end{array}$ & $\begin{array}{l}\text { Expensive, need diluted } \\
\text { medium, highly sensitive to } \\
\text { pH changes, difficult resin } \\
\text { regeneration etc. }\end{array}$ & {$[18,76-78]$} \\
\hline $\begin{array}{l}\text { Chemical } \\
\text { Precipitation }\end{array}$ & $\begin{array}{l}\text { Precipitating agents as lime, } \\
\text { pyrite, sulfides, chelating agents. }\end{array}$ & $\begin{array}{l}\text { Efficiently able to clean up to } \\
\text { ppm level, selective metal } \\
\text { precipitation is possible. }\end{array}$ & $\begin{array}{l}\text { Complex, require toxic and } \\
\text { corrosive chemicals, cost } \\
\text { effective, difficult disposal of } \\
\text { sludge, largely effected by pH } \\
\text { change, nonselective, }\end{array}$ & {$[9,88-90]$} \\
\hline
\end{tabular}


Table 1. Cont.

\begin{tabular}{cccc}
\hline Techniques & Materials used & Advantages & Disadvantages \\
\hline Reverse Osmosis & Semi-permeable membranes & $\begin{array}{c}\text { Complex, nonselective, } \\
\text { Able to remove most of the } \\
\text { pollutants }\end{array}$ & $\begin{array}{c}\text { Continuous energy input, plug } \\
\text { fouling, Low efficiency, Slow } \\
\text { removal rate. }\end{array}$ \\
\hline Electro-chemical & $\begin{array}{c}\text { Specific electrode materials, } \\
\text { hybrid electrodes, coated } \\
\text { electrode etc. }\end{array}$ & $\begin{array}{c}\text { Highly specific, able to } \\
\text { remove suspended solids, } \\
\text { dissolved metals. }\end{array}$ & $\begin{array}{c}\text { High cost electrode required, } \\
\text { need continuous energy input, } \\
\text { higher cost, highly sensitive to } \\
\text { pH changes. }\end{array}$ \\
\hline
\end{tabular}

Carbon (carbon nanotubes (CNTs), fullerenes, graphene, and graphene derivatives) based adsorbent materials are being used for the effective removal of the heavy metal ions because of their extraordinary high surface area to volume ratio and light weight as compared to other materials $[66,96$, 97]. Currently, adsorbents based on the carbon nanotubes [98,99], activated carbon [100-105], graphene/ graphene oxide (GO) [60,67,106-117], graphene magnetite's [118-123] polymeric adsorbents [124-132] and other type of adsorbents [133-137] have attracted substantial attention for the removal of heavy metal ions from the wastewaters. Carbon nanotubes have significant adsorption capacities for the effective removal of heavy metal ions from aqueous solutions as compared to non-functionalized and activated carbon-based adsorbents [99,138-142]. Although, carbon nanotubes-based materials are the promising adsorbents but their high cost and lower availability, limit the large-scale applications as adsorbents. In addition to this, water permeation through CNTs membranes is a major concern which is still unclear even after both the experimentally and molecular dynamic studies. Therefore, economic, readily available, and effective adsorbents are the prime concern of the $21^{\text {st }}$ century for the effective removal of heavy metal ions from wastewaters. Although, the presence of humic substances has strong complexation binding ability with metal ions because of their abundant oxygen-containing functional groups, yet graphene-based adsorbents have been proven the best substituents for the removal of heavy metal ions from aqueous medium $[66,67,143]$. Therefore, the adsorption behavior of heavy metal ions onto the surface of graphene-based nanoadsorbents is the chief concern of this study.

Graphene, a flat, single-atom thick sheet of $\mathrm{sp}^{2}$-hybridized carbon atoms with a two-dimensional honeycomb densely packed lattice arrangement, is an essential non-classical carbon adsorbent [144]. Graphene has a variety of real-time applications because of its extraordinary excellent thermal, mechanical and electrical properties [145]. Graphene is considered a promising material for the comprehensive adsorption of wide variety of pollutants from aqueous systems owing to its theoretically large specific surface area to volume ratio $\left(\approx 2675 \mathrm{~m}^{2} / \mathrm{g}\right)$, high Young's Modulus $\left(1.06 \times 10^{3}\right.$ Gegapascals $)$ and high thermal conductivity $\left(3 \times 10^{3}\right.$ Watt per meter kelvin) $[113,146]$. The wet chemical redox process is one of the most effective method for the production of graphene from graphite, where GO is an intermediate with a high density of negatively-charged reactive functional groups, viz. hydroxyl, carboxylic, and epoxy groups [147-149]. The presence of several functional groups makes GO soluble in polar and non-polar solvents as the oxygen functionality makes GO hydrophilic and the graphene domain makes GO hydrophobic. All the functional groups present on the edges and on the basal plane of GO play an important role in the heavy metal ions removal process [150]. Therefore, GO could be the best potential scavenger for the effective removal of cationic pollutants through electrostatic interactions between the positively-charged pollutants and negatively-charged functional groups of GO $[27,151]$. The relative high surface area, surface functionality, and better conductivity of graphene sheets play a key role in the better adsorption of several heavy metal ions through the preconcentration of aqueous medium $[67,144]$. Nair et al. reported that a few layered thick GO sheet membrane can completely block the passage of pollutants in the form of liquids and gases in a dry state while facilitating the permeation of water vapors [152]. On the other hand, aggregation, which is a major disadvantage of graphene layers, could be prevented partially through its composite formation $[41,153]$. In addition, composite formation may impart enhanced efficiency for the removal of heavy metal ions from wastewater due to the synergistic effects of the materials used. Electrosorption, a simple, novel, 
ecofriendly and recently attractive heavy metal ions adsorption technique which does not requires toxic or non-toxic chemicals and involves ideal nanostructured materials with a high surface area (such as activated carbon, carbon nanotubes, and carbon aerogels) onto which an external electric field is applied to remove metal ions from aqueous solutions [93,154-157]. Hence, this review includes various surface modification approaches and post synthesis, assembly steps, which will enable the exploitation of GO as a novel adsorbent material for cost effective water purification and the removal of heavy metals through graphene and its composites, which may be helpful in the purification of potable and safe drinking water as well as the removal of heavy metal ions from wastewaters and to clean up the environmental problems.

\section{Removal of Lead}

$\mathrm{Pb}$ (II) is one of the most useful heavy metal with wide spectrum applications worldwide. On the other hand, the presence of $\mathrm{Pb}$ (II) in aqueous system is a major threat to mankind as well as to the ecosystem owing to its high toxicity. Therefore, removal of $\mathrm{Pb}$ (II) ions from the wastewater aqueous system is quite essential to diminish the toxic threats. An adsorption process is largely dependent on the surface area and pore size of the adsorbents, whereas, the adsorption of metal ions is based on chemical adsorption onto specific adsorption sites, i.e., adsorption capacity of an adsorbent increases with the increase of its functional groups $[158,159]$. Graphene is thanked to have several active functional groups such as carboxylic, hydroxyl, and epoxy functional groups acting as better adsorption sites [160-163]. Hence, graphene and graphene derivatives due to their easy preparation, surface modifications, bulk availability and high adsorption capacities have been extensively studied for the removal of $\mathrm{Pb}$ (II) ions from aqueous system. Graphene based nanoadsorbents preparation, characterization and their applications for the removal of $\mathrm{Pb}$ (II) ions from aqueous medium as well as adsorption process and kinetic studies have been reviewed.

\subsection{Removal of lead using functionalized $G O / R G O / G O-a e r o g e l$}

An adduct of GO and EDTA, was prepared using silylation by reacting N-(trimethoxysilylpropyl) ethyledinediamine triacetic acid (EDTA-silane) with the -OH functionality of the GO layers [164]. Hummer's and Offeman's modified double stage oxidation process was used to produce GO. In the first preoxidized step, natural graphite was treated with potassium persulfate and phosphorous pentaoxide in sulfuric acid followed by the oxidation with potassium permanganate, conc. sulfuric acid and hydrogen peroxide. GO was filtered and washed with $0.1 \mathrm{M} \mathrm{HCl}$ and deionized water. Resulting GO was then reacted through silylation process with EDTA-silane and was filtered followed by repeatedly washing with methanol and water. For comparison, a reduced GO adduct, EDTA-RGO black was prepared by direct thermal reduction treatment at $30{ }^{\circ} \mathrm{C}$ for $30 \mathrm{~min}$. Adsorption isotherms analysis was performed in a plastic vial using $10 \mathrm{mg}$ or $25 \mathrm{mg}$ adsorbent to a 100 or $200 \mathrm{~mL}$ solution of $\mathrm{Pb}$ (II) ions at room temperature. It is evident that the adsorption of positively-charged metal ions depend on the charge present on the surface of the adsorbents as functionalities $[165,166]$. Zeta potential of the adsorbents at different $\mathrm{pH}$ was determined using Nano-ZS, Zeta Sizer and correlated with the adsorption of $\mathrm{Pb}$ (II) ions. At a particular $\mathrm{pH}$, more negative zeta potential indicated the highest carboxylic and hydroxyl functionalities on the surface of EDTA-GO and GO adsorbents than activated carbon and EDTA-RGO was found to be consistent with Boehm's titration results [167-170].

The enhanced adsorption for $\mathrm{Pb}(\mathrm{II})$ ions from the aqueous solution was observed with an EDTA-GO adduct (Figure 1) when compared with GO and EDTA-RGO adduct. The maximum adsorption capacities of the EDTA-GO adduct and GO for $\mathrm{Pb}$ (II) were found to be $479 \pm 46$ and $328 \pm 39 \mathrm{mg} / \mathrm{g}$, respectively, which were greater than those of oxidized carbon nanotubes and activated carbon-based adsorbents [164]. The superior performance of EDTA-GO was correlated with the chelating characteristics of EDTA with functionalized graphene sheets. Mainly two adsorption process were considered to be responsible for the improved efficiency of removal of $\mathrm{Pb}$ (II) ions with the EDTA-GO adduct, i.e., the ion-exchange reaction process (Scheme 1) between $\mathrm{Pb}(\mathrm{II})$ and carboxylic 
and hydroxyl functional groups responsible for chelate complex formation between $\mathrm{Pb}(\mathrm{II})$ and EDTA onto the GO surface, as shown below.

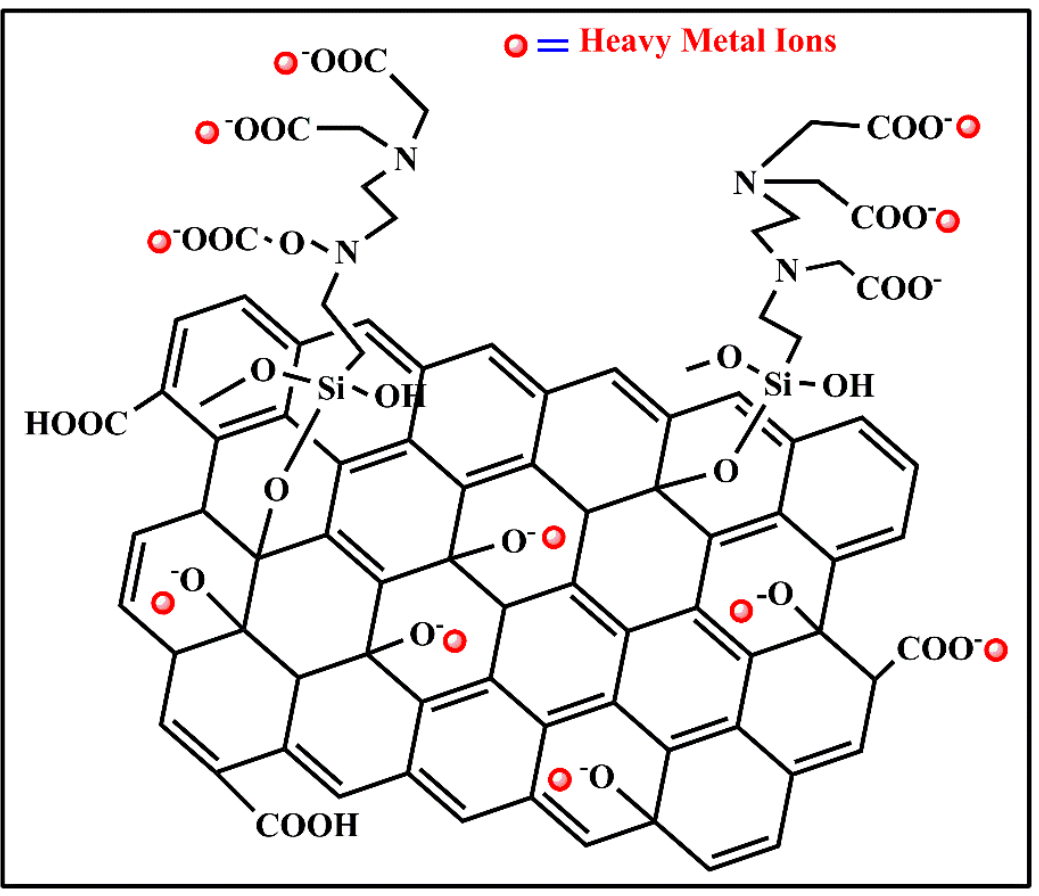

Figure 1. Heavy metal ions adsorption on EDTA-GO adduct surface [164].

(First adsorption type):

Interactions of $\mathrm{Pb}$ (II) ions onto the surface of $\mathrm{GO}$ to form the complex:

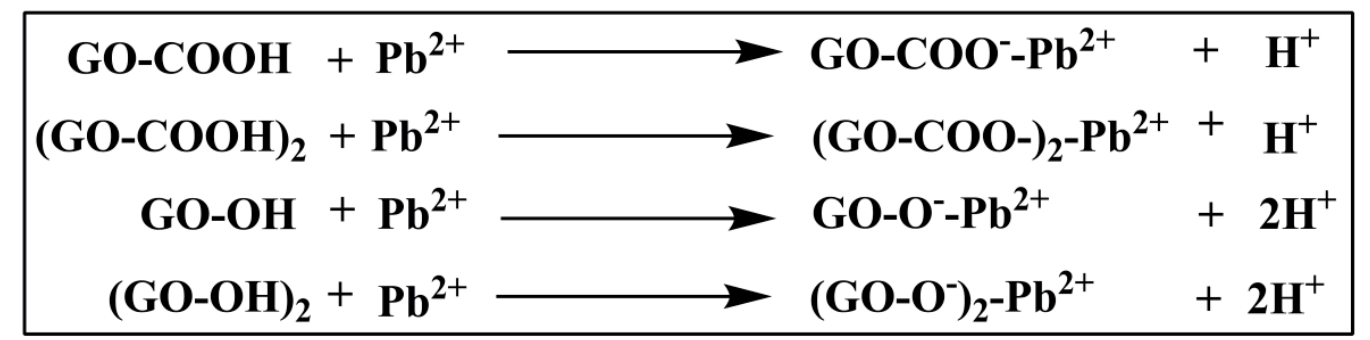

Scheme 1. Adsorption of $(\mathrm{Pb}) \mathrm{II}$ ions based on ion-exchange process [164].

(Second adsorption type may include):

Complex formation of $\mathrm{Pb}(\mathrm{II})$ with $-\mathrm{COOH}$ :

\begin{tabular}{|l} 
GO-EDTA-COOH $+\mathrm{Pb}^{2+} \longrightarrow$ GO-EDTA-COO- $^{-} \longrightarrow \mathrm{Pb}^{2+}+\mathrm{H}^{+}$ \\
$(\mathrm{GO}-\mathrm{EDTA-COOH})_{2}+\mathrm{Pb}^{2+}$
\end{tabular}

Scheme 2. Adsorption of $\mathrm{Pb}(\mathrm{II})$ ions involving complex forming of EDTA with $\mathrm{Pb}$ (II) [164].

The second adsorption mechanism involves the stable complex formation of EDTA with $\mathrm{Pb}$ (II) ions for the complete removal of $\mathrm{Pb}$ (II) ions from aqueous solution (Scheme 2). After adsorption, $\mathrm{Pb}$ (II) equilibrium concentration reached lower than food and drug administration drinking water concentration i.e $<10 \mathrm{ppm}$. Higher adsorption capacity was attributed with the higher stability constant $(\log \mathrm{K} \approx 18.0)$ of $\mathrm{Pb}(\mathrm{II})$-EDTA complex. Langmuir and Freundlich adsorption isotherms exhibited 
good agreement with the experimental data having a correlation coefficient $\left(\mathrm{R}^{2}\right) 0.975$ and 0.933 at $\mathrm{pH}$ 6.8 respectively. The adsorption phenomenon rate for $\mathrm{Pb}$ (II) ions onto the surface of EDTA-GO was found to be $\mathrm{pH}$ dependent. It was noted that as $\mathrm{pH}$ of the aqueous medium increased from 5.0 to 8.0 , adsorption capacity of EDTA-GO also increased due to chelate formation of $\mathrm{Pb}$ (II) with the hydroxyl, carboxylic functional groups of GO and EDTA. Low adsorption at high acidic medium was attributed due to neutralization of $\mathrm{COO}^{-}$and $\mathrm{O}^{-}$surface charges and relative competition between proton and $\mathrm{Pb}$ (II) ions. Lower zeta potential until $\mathrm{pH} 8.0$ indicated that there were enough negative charge density to provide the strong electrostatic attraction between adsorbent's functional group and $\mathrm{Pb}$ (II) ions. However, as the $\mathrm{pH}$ of the medium increased from 8.0, zeta potential rise indicated that negative charge density decreased and $\mathrm{Pb}(\mathrm{II})$ ions hydrolzse to give $\mathrm{Pb}(\mathrm{OH})^{+}, \mathrm{Pb}(\mathrm{OH})_{2},\left[\mathrm{~Pb}(\mathrm{OH})_{3}\right]^{-},\left[\mathrm{Pb}_{3}(\mathrm{OH})_{4}\right]^{2+}$ $\left[\mathrm{Pb}_{2}(\mathrm{OH})_{2}\right]^{2+}\left[\mathrm{Pb}_{6}(\mathrm{OH})_{8}\right]^{4+}$ and $\left[\mathrm{Pb}_{4}(\mathrm{OH})_{4}\right]^{4+}[171-173]$. As it is desirable to have appropriate both the adsorption and desorption capacities to be an economical and ideal adsorbent, desorption experiments at different $\mathrm{pH}$ were carried out using $\mathrm{Pb}$ (II) pretreated EDTA-GO to determine desorption capacity. Desorption rate of $\mathrm{Pb}(\mathrm{II})$ was found to be maximum in acidic medium as consistent with zeta potential indicated that at lower $\mathrm{pH}$, neutralization of functional groups leads to the competition between proton and $\mathrm{Pb}$ (II) ions adsorption [174]. Atomic absorption spectroscopy results were found to be in good agreement indicated that $\mathrm{Pb}(\mathrm{II})$ ions could be repeatedly desorbed from EDTA-GO adsorbent even after 10 cycles.

Varadwaj et al. prepared Mg-Al-layered double hydroxide and partially reduced GO (LDH/pRGO) nanocomposites by a two-step process, resulting a three-dimensional highly porous nanocomposite adsorbent [174]. GO nanosheets were obtained using the modified Hummer's method and in situ homogeneously LDH nanosheets were grown onto the surface of GO by a crystallization and facile supersaturation coprecipitation technique at $\mathrm{pH} 10$ [175]. Typically, a mixed metal solution of $\mathrm{Mg}(\mathrm{NO})_{3} \cdot 6 \mathrm{H}_{2} \mathrm{O}$ and $\mathrm{Al}\left(\mathrm{NO}_{3}\right)_{3} \cdot 9 \mathrm{H}_{2} \mathrm{O}$ and alkaline solution of $\mathrm{Na}_{2} \mathrm{CO}_{3}$ and $\mathrm{NaOH}$ were added dropwise simultaneously to GO ultrasonicated solution at $10 \mathrm{pH}$. After the stipulated period of time, precipitate was filtered and washed with deionized water and dried at $100{ }^{\circ} \mathrm{C}$ for $24 \mathrm{~h}$. It was supposed that $\mathrm{Mg}^{2+}$ and $\mathrm{Al}^{3+}$ ions form coordination complexes with the carboxylic, hydroxyl and carbonyl functional groups of $\mathrm{GO}$ upon simultaneous alkaline precipitating agents and weakened the $\mathrm{C}=\mathrm{O}$ str. absorption peak in FT-IR (Fourier transform infrared spectroscopy) spectrum at $1729 \mathrm{~cm}^{-1}$ indicating the partial reduction of GO in Mg-Al-LDH/pRGO composite and was in consistent with $0.65 \mathrm{~nm}$ shifting of (001) basal spacing X-ray diffraction peak. Disappearance of pRGO diffraction peaks from Mg-Al-LDH-pRGo composite exhibited the complete exfoliation of pRGO sheets. Further, GO and $\mathrm{Mg}-\mathrm{Al}-\mathrm{LDH} / \mathrm{pRGO}$ were exploited under nitrogen adsorption-desorption studies which revealed that meso-porous structural morphology related to narrow slit-like pores for GO and interconnected pore network for Mg-Al-LDH/pRGO composite. BET (Brunauer-Emmett-Teller) surface area, pore volume and pore size indicated increasing trend as the metal ion concentration of LDH increases. An increase surface area with crosslinked network is supposed to offer more active sites for better metal ions adsorption from the aqueous solution.

Figure 2 presents $\mathrm{pH}$ based adsorption efficiency for $\mathrm{Pb}(\mathrm{II})$ for $24 \mathrm{~h}$ contact time at $100 \mathrm{mg}$ $\mathrm{dm}^{-3}$ as an initial $\mathrm{Pb}$ (II) ion concentration. The highest adsorption efficiency was observed for the Mg-Al-LDH/pRGO composite adsorbent as compared to LDH, GO, and pRGO, which might be correlated with the synergistic effects of LDH and GO. The adsorption efficiency of the adsorbent was found to be lowest in acidic medium and increased with increasing $\mathrm{pH}$ of the medium. The lower adsorption in the acidic medium was attributed due to the competitive presence of $\mathrm{H}^{+}$ions. As the basicity of the medium increased, the concentration of $\mathrm{H}^{+}$ions decreased, resulting in higher $\mathrm{Pb}$ (II) ion adsorption. Owing to the subsequent precipitation of $\mathrm{Pb}(\mathrm{II})$ ions as $[\mathrm{Pb}(\mathrm{OH})],\left[\mathrm{Pb}(\mathrm{OH})_{2}\right],\left[\mathrm{Pb}(\mathrm{OH})_{3}\right]^{-}$, $\left[\mathrm{Pb}_{3}(\mathrm{OH})_{4}\right]^{2+}\left[\mathrm{Pb}_{2}(\mathrm{OH})_{2}\right]^{2+}\left[\mathrm{Pb}_{6}(\mathrm{OH})_{8}\right]^{4+}$, and $\left[\mathrm{Pb}_{4}(\mathrm{OH})_{4}\right]^{4+}$ in basic medium, the $\mathrm{pH}$ of the medium was set to 4.5 for all other experimental studies to avoid precipitation and to confirmed the removal of $\mathrm{Pb}$ (II) ions through adsorption [173]. Higher adsorption efficiency was obtained with higher " $x$ " values of LDH due to the increasing high surface area and pore volume with increasing " $x$ " factor. 
The pore sizes of 10.97-21.23 nm of the resulting interconnected 3D network allows the easy flow of hydrated $\mathrm{Pb}$ (II) ions, which have $\sim 0.4 \mathrm{~nm}$ radius. In addition, the availability of more active sites due to the high surface area accounted for the higher adsorption efficiency of the 3D interconnected nano-porous adsorbent. As the adsorption efficiency depends not only on the surface area but also on the interactive strength of the surface functional groups, hence zeta potential was used to explain electrostatic interactions between the adsorbent and adsorbate. Zeta potential decreased as the $\mathrm{pH}$ of the medium increased suggesting that there were higher availability of negative charges which were responsible for the strong electrostatic interactions between positively-charged metal ions and negatively-charged adsorbent's surface.
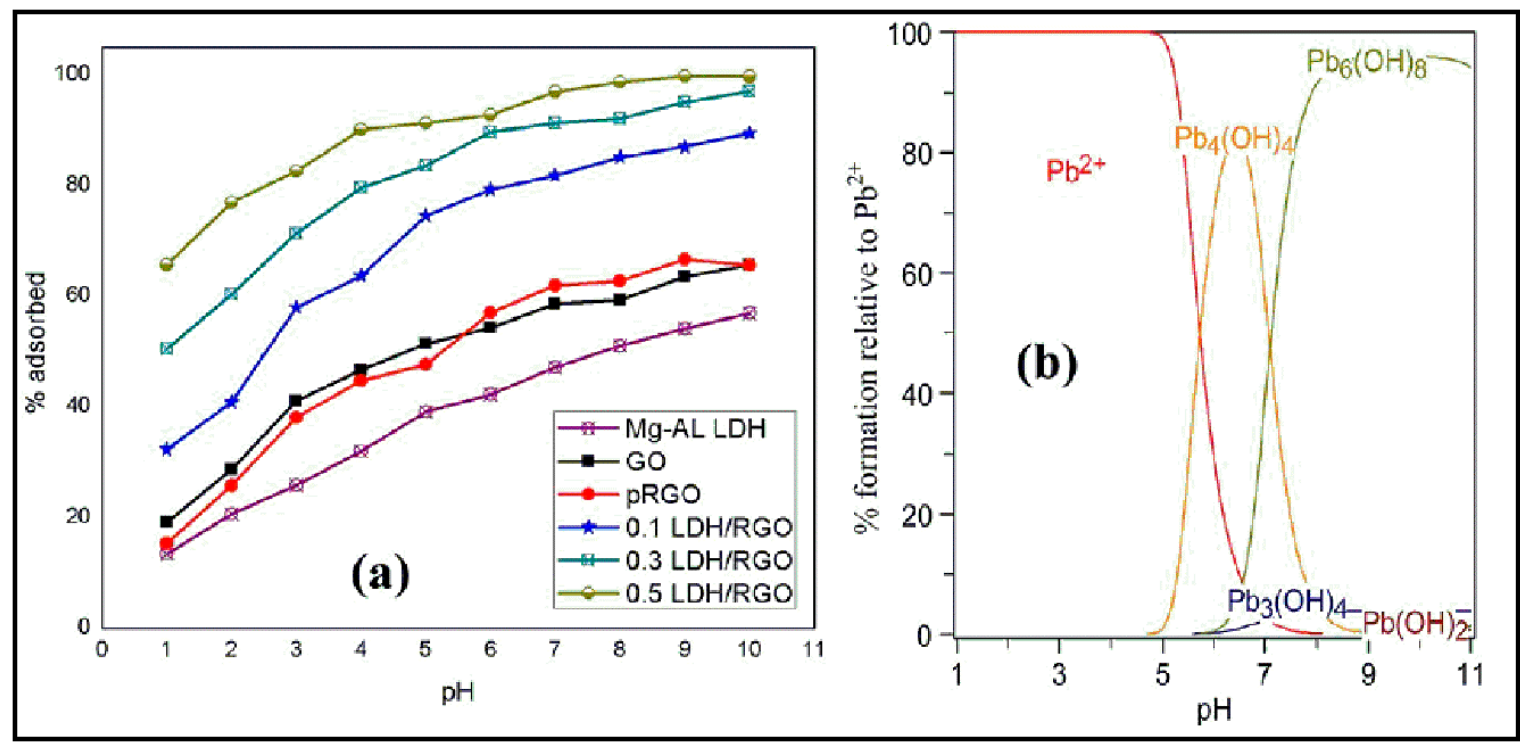

Figure 2. (a) Adsorption efficiency of LDH, GO, pRGO, and $x \mathrm{Mg}-\mathrm{Al} \mathrm{LDH} / \mathrm{pRGO}$ adsorbents at $\mathrm{pH} 1$ to 10. (b) Speciation of $\mathrm{Pb}(\mathrm{II})$ as a function of $\mathrm{pH}$ [174].

Effect of temperature is an important factor of study on which the adsorption phenomenon depends because the adsorption rate depends on the solution viscosity, electrostatic interactions between the metal ions and the adsorbent surface, diffusion of the adsorbents and structural morphology of the adsorbent at a particular temperature. These factors are responsible for maximizing $\mathrm{Pb}$ (II) ions uptake due to the increased mobility of $\mathrm{Pb}(\mathrm{II})$ ions towards active sites of the adsorbents $[166,176,177]$. It was noted that as the temperature increased, the adsorption capacities of GO and pRGO increased which were ascribed with the decreased viscosity of the medium, increased mobility of $\mathrm{Pb}(\mathrm{II})$ ions, and increased pore volume and structural porosity at a higher temperature indicating endothermic nature of adsorption whereas temperature rise sometime may lead to decreased in adsorptive forces affecting adsorption rate [166]. Langmuir adsorption isotherms assumed uniform monolayer surface adsorption. $\mathrm{Pb}$ (II) ions adsorption was found to be increased with temperature. Increasing adsorptive strength of adsorbents indicated increasing strong interactions between adsorbents reactive sites and $\mathrm{Pb}$ (II) ions with increasing adsorbate temperature $[163,166,178]$.

Thermodynamic parameters viz. Gibbs free energy $\left(\Delta \mathrm{G}^{\circ}\right)$, enthalpy $\left(\Delta \mathrm{H}^{\circ}\right)$ and entropy $\left(\Delta \Sigma^{\circ}\right)$ obtained indicated spontaneous adsorption process [179]. Negative values for $\Delta \mathrm{G}^{\circ}$ demonstrated the spontaneity of adsorption process and adsorption was found to be increased as the temperature increased. Positive values for $\Delta \mathrm{H}^{\circ}$ and $\Delta \Sigma^{\circ}$ for $0.5 \mathrm{Mg}$-Al-LDH/pRGO denoted endothermic adsorption and increased in the disorderliness at solid-solution interface. It was interested to note that the physiosorption was predominated for low " $x$ " factor i.e., 1.0 and 3.0 Mg-Al-LDH/pRGO nanocomposites whereas adsorption for GO, pRGO and $0.5 \mathrm{Mg}-\mathrm{Al}-\mathrm{LDH} / \mathrm{pRGO}$ was facilitated by both chemisorption and physiosorption process. Desorption experiments were carried out using $0.1 \mathrm{M} \mathrm{HCl}$ and $0.01 \mathrm{M}$ 
EDTA solutions to get insight into the recovery of metal ions on the spent adsorbents and the possible regeneration of the adsorbent for reuse [174]. Both insights may help to minimize the disposal of spent adsorbent, and reduce the production of secondary pollutants. Compared to EDTA solution used, better adsorbent regeneration was achieved with $0.1 \mathrm{~mol} \mathrm{dm}^{-3} \mathrm{HCl}$ solution, which demonstrated the effective ability of $\mathrm{HCl}$ to regenerate the spent adsorbent which could be further reused for other industrial applications, such as electroplating.

Nitrogen-doped graphene aerogels (NGAs) were prepared via a facile one-pot hydrothermal route and used as the electrode material for the electrosorption of $\mathrm{Pb}$ (II) ions as depicted in Scheme 3 [180]. The insertion of heteroatoms (strong coordination ability with metal cations) onto carbon and graphene-based nanomaterials enhance the adsorption capacity because heteroatoms can coordinate strongly with heavy metal ions [181]. NGAs was prepared by hydrothermal treatments of GO and urea homogenous suspension for $12 \mathrm{~h}$ at $180^{\circ} \mathrm{C}$ in Teflone lined autoclave. Resulted samples were immersed in pure water for $72 \mathrm{~h}$ to remove impurities by changing water at every $4 \mathrm{~h}$ and freeze-dried at $-52{ }^{\circ} \mathrm{C}$ to obtain NGAs which was used for the electrosorption of $\mathrm{Pb}$ (II) ions as paper electrode. Appearance of new XPS (X-ray photoelectron spectroscopy) peaks at $400.0 \mathrm{eV}$ and $285.8 \mathrm{eV}$ indicated the incorporation of nitrogen and $\mathrm{C}-\mathrm{N}$ bond formation after hydrothermal treatment respectively. Deconvolution spectrum fitted for N 1s into three XPS peaks at 398.1, 399.5, and $401.4 \mathrm{eV}$ were found to be corresponded with pyridinic $\mathrm{N}$, pyrrolic $\mathrm{N}$ and graphitic $\mathrm{N}$, respectively.

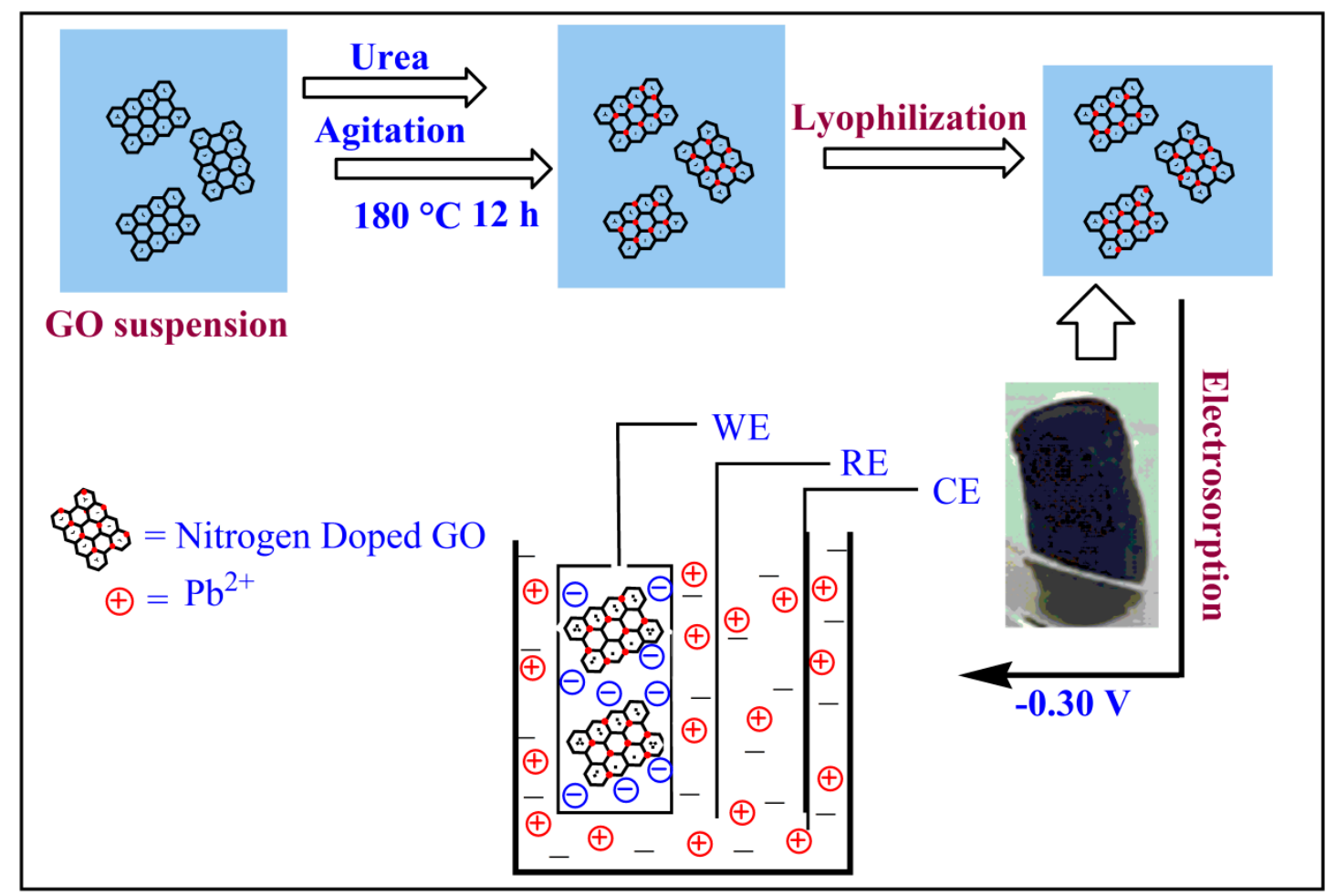

Scheme 3. Preparation of NGAs and electrosorption of $\mathrm{Pb}$ (II) ions [180].

The electrosorption experiment for $\mathrm{Pb}$ (II) was performed using a conventional three-electrode system consisting of NGAs paper, saturated calomel electrode (SCE), and platinum foil as working, reference, auxiliary electrodes, respectively. NGAs paper electrode showed highest electrosorption of $\mathrm{Pb}$ (II) ions in the shortest adsorption equilibrium time (within $5 \mathrm{~s}$ ) at $-0.3 \mathrm{~V}(1 \mathrm{mM}, \mathrm{pH} 4.2)$ potential applied when compared with GAs, and RGO. The superior electrosorption behavior for $\mathrm{Pb}$ (II) could be attributed due to the synergistic effects of both NGAs (with a larger surface area $\sim 434.4 \mathrm{~m}^{2} \mathrm{~g}^{-1}$ ) and incorporated heteroatoms which result electrosorption through the electrostatic attractions derived from an external electric field, electrostatic attraction caused by intrinsic charges on the NGAs and 
$\mathrm{Pb}(\mathrm{II})$, and strong coordination between the doped nitrogen atoms and $\mathrm{Pb}(\mathrm{II})$ ions. The highest metal ion removal ratio $(\% R)$ was found to decline continuously with an increased initial concentration of $\mathrm{Pb}$ (II) ions indicating NGAs as a promising electrode material for $\mathrm{Pb}$ (II) ions electrosorption at low concentration [182,183].

The electrosorption data were fitted with Langmuir and Freundlich models. The correlation coefficient $\left(\mathrm{R}^{2}\right)$ for the Freundlich model was closer to 1 as compared with Langmuir model (0.9778 vs. 0.8651), which suggests that the electrosorption of $\mathrm{Pb}(\mathrm{II})$ by the NGAs electrode could be modelled more accurately by the Freundlich model. The $\mathrm{R}^{2}$ value obtained for pseudo first- $(0.8465)$ and second-order kinetics (0.9984) showed that the electrosorption kinetics for $\mathrm{Pb}$ (II) onto the NGAs electrode was a better fit to the pseudo-second-order model. Recyclability of used electrode is another important characteristics of electrosorption, i.e., reversible electrosorption and electrodesorption for the same electrode material could be easily achieved using variable potential. NGAs exhibited a highest metal ions removal ratio even after 100 electrosorption/electrodesorption than the previous reports [184-187].

Graphene oxide/ nickel foam (GO/NF) synthesized via vacuum impregnation method was used for $\mathrm{Pb}(\mathrm{II})$ ions electrosorption by Song et al. [188]. To prepare electrode, the appropriate size of NF sheet was washed with acetone followed by hydrochloric acid and deionized water which then immersed in GO solution for $2 \mathrm{~h}$ at $40{ }^{\circ} \mathrm{C}$ under vacuum. The composite was washed with deionized water and dried under vacuum. GO/NF electrode was installed in $\mathrm{Pb}\left(\mathrm{NO}_{3}\right)$ tank for $\mathrm{Pb}$ (II) ions electrosorption studies. $\mathrm{pH}$ is an important factor which greatly affects the adsorption of $\mathrm{Pb}$ (II) ions hence, studied first. $\mathrm{pH}$ study range was set from 3.0 to 6.0, since, $\mathrm{Pb}$ (II) ions get precipitated as $[\mathrm{Pb}(\mathrm{OH})],\left[\mathrm{Pb}(\mathrm{OH})_{2}\right],\left[\mathrm{Pb}(\mathrm{OH})_{3}\right]^{-},\left[\mathrm{Pb}_{3}(\mathrm{OH})_{4}\right]^{2+}\left[\mathrm{Pb}_{2}(\mathrm{OH})\right]^{2+}\left[\mathrm{Pb}_{6}(\mathrm{OH})_{8}\right]^{4+}$, and $\left[\mathrm{Pb}_{4}(\mathrm{OH})_{4}\right]^{4+}$ above $\mathrm{pH} 6.0$ [189] Electrosorption capacity of $\mathrm{GO} / \mathrm{NF}$ was found to be increased with decreasing medium acidity. $\mathrm{pH} 5.0$ was found the appropriate condition for electrosorption as the steady adsorption capacity was observed above $5.0 \mathrm{pH}$. Lower adsorption capacity of GO/NF at low $\mathrm{pH}$ was correlated with the competitive adsorption between $\mathrm{H}^{+}$and $\mathrm{Pb}$ (II) ions as reported in literature $[189,190]$. Whereas, on increasing $\mathrm{pH}, \mathrm{H}^{+}$ions competition weaken and $\mathrm{Pb}(\mathrm{II})$ ions adsorption increased. It was interesting to note that GO coating largely enhanced the adsorption capacity of GO/NF $(193 \mathrm{mg} / \mathrm{g}$ at $100 \mathrm{mg} / \mathrm{L}$ as initial concentration) for $\mathrm{Pb}$ (II) ions without applying any voltages when compared with virgin $\mathrm{NF}$ owing that $\mathrm{GO}$ had large negatively-charged oxygenated surface which favored $\mathrm{Pb}$ (II) ions adsorption. Electrosorption capacity of $\mathrm{GO} / \mathrm{NF}$ (663mg/g, approx. three times) increased when electric current of $1.2 \mathrm{~V}$ was applied at the same initial $\mathrm{Pb}(\mathrm{II})$ ions concentration indicated that external electric field driven effectively the adsorption of $\mathrm{Pb}$ (II) ions adsorption. Langmuir adsorption isotherms of $\mathrm{Pb}$ (II) on $\mathrm{GO} / \mathrm{NF}$ electrode were found to be better fitted with higher correlation coefficient $\left(R^{2}=0.9795\right)$ and maximum adsorption capacity $(3690.37 \mathrm{mg} / \mathrm{g})$ than Freundlich. GO/NF showed extremely higher electrosorption capacity, indicating the great potential for $\mathrm{Pb}$ (II) ions adsorption from aqueous system in comparison to other adsorbents. Electrosorption mechanism for $\mathrm{Pb}$ (II) ions onto the surface of $\mathrm{GO} / \mathrm{NF}$ surface was analyzed using XPS indicating new $\mathrm{Pb} 4 \mathrm{f}$ peak at $183.3 \mathrm{eV}$ after successful adsorption. Noticeable decreased in relative $\mathrm{C}-\mathrm{OH}$ bond area from $26.98 \%$ to $7.98 \%$ and increased bond area ratio of $-\mathrm{C}=\mathrm{O}$ from $11.92 \%$ to $13.05 \%$, clearly indicated, surface adsorption of $\mathrm{Pb}(\mathrm{II})$ ions, facilitated by hydroxyl and carboxylic functional groups. Mono or multilayers coating of GO not only increased surface area of $\mathrm{GO} / \mathrm{NF}$ but also provided more space for double layer electrosorption/chemisorption of $\mathrm{Pb}$ (II) ions.

Electron beam irradiation is another cost-effective and environment friendly method that can be applied to all material phases (i.e., solid, liquid, and gas,) at a low temperatures and can be scaled up easily [172]. Therefore, Bai et al. synthesized GO with a controlled oxygen content using electron beam irradiation and used $\mathrm{Pb}(\mathrm{II})$ metal ions adsorption [191]. Before the preparation of GO, graphite was placed on stainless steel plate uniformly and irradiated with different intensity dosages of 6.4 and $19.2 \mathrm{kGy}$ by changing irradiation period of time. GO was prepared using modified Hummer's method and dried under vacuum for $48 \mathrm{~h}$ at $40{ }^{\circ} \mathrm{C}$. Irradiated GO was then examined under the effects of the contact time, $\mathrm{pH}$ of the medium, initial concentration of $\mathrm{Pb}$ (II) ions $(75 \mathrm{mg} / \mathrm{L})$, and ionic strength for $\mathrm{Pb}(\mathrm{II})$ ions sorption. After the sorption process, solution was filtered and $\mathrm{Pb}$ (II) ion 
concentrations remaining were examined by inductively coupled plasma with an optical emission spectrometer. The removal capacities of the adsorbent $\mathrm{q}_{\mathrm{e}}(\mathrm{mg} / \mathrm{g})$ were calculated using the equation, $\mathrm{q}_{e}=\left(\mathrm{C}_{i}-\mathrm{C}_{e}\right) \mathrm{V} / \mathrm{m}$, where $\mathrm{C}_{i}$ and $\mathrm{C}_{e}$ are the initial and equilibrium $\mathrm{Pb}(\mathrm{II})$ ion concentrations $(\mathrm{mg} / \mathrm{L})$, respectively; $\mathrm{V}$ is solution volume in $\mathrm{mL}$; and $\mathrm{m}$ is amount of the adsorbent in $\mathrm{mg}$. The amount of $\mathrm{Pb}$ (II) adsorbed onto the GO surface increased remarkably with increasing adsorption time and the equilibrium was reached within $20 \mathrm{~min}$. Hence, a maximum of $2 \mathrm{~h}$ of contact time was found to be adequate to achieve sorption equilibrium. The increased sorption with the irradiation dose and time indicated that higher functionality formed through higher irradiated dosages which were responsible for higher $\mathrm{Pb}(\mathrm{II})$ ions sorption onto GO surface. The experimentally obtained $\mathrm{Pb}$ (II) ions sorbed amount was very close with the calculated value as per nonlinear pseudo-second-order rate model. The correlation coefficients obtained from the pseudo-second order kinetic model simulations were near to 1.0, indicating that sorption of $\mathrm{Pb}$ (II) onto the $\mathrm{GO}$ surface might be controlled mainly by the chemical adsorption processes (chemisorption) and the equilibrium sorption capacity was almost proportional to the number of occupied active positions on the GO surface, which increased with increasing irradiation dose. Another important parameter, effects of $\mathrm{pH}$ on the adsorption of $\mathrm{Pb}$ (II) ions was studied with an initial $\mathrm{Pb}$ (II) ions concentration of $75 \mathrm{mg} / \mathrm{L}$ and $1.5 \mathrm{mg}$ of GOs for $2 \mathrm{~h}$ of contact time. The adsorption capacity of the GOs increased with increasing $\mathrm{pH}$ from 1-5, as reported previously $[164,174]$. The hydrogen ion concentration rendered the adsorption of $\mathrm{Pb}$ (II) at a lower $\mathrm{pH}$ because it neutralized the carboxylic and hydroxyl functionalities. The concentration of negative functional groups, such as $\mathrm{COO}^{-}$and $\mathrm{O}^{-}$, increased with increasing $\mathrm{pH}$, which were responsible for the better adsorption of $\mathrm{Pb}(\mathrm{II})$ at higher $\mathrm{pH}$. Effect of ionic strength on $\mathrm{Pb}$ (II) ions adsorption was found fairly negligible and independent in the range of 0.001-0.1 mol/L for different dosages of GO however it was largely dependent on $\mathrm{pH}$ which indicated inner-sphere surface complexation (chemisorption) rather than outer-sphere surface complexation of $\mathrm{Pb}(\mathrm{II})$ ions onto the GO surface $[26,171,192]$.

\subsection{Removal of lead using GO-polymer composites}

To prevent the aggregation of GO nanosheets, poly(3-aminopropyltriethoxysilane) (PAS) oligomers were cross-linked three dimensionally with GO nanosheets to obtain a high performance adsorbent, PAS-GO [193]. Three-dimensional crosslinking network was meant to prevent the aggregation of GO nanosheets, to provide easy accessibility for foreign molecules and to introduce a large amount of amino functional groups for better adsorption of $\mathrm{Pb}(\mathrm{II})$ ions. Two new absorption peaks in FT-IR spectrum of PAS-GO at $3430 \mathrm{~cm}^{-1}$ for $-\mathrm{NH}_{2}$ stretching and at $2927 \mathrm{~cm}^{-1}$ for $-\mathrm{CH}_{2}$ stretching vibrations indicated oligomers crosslinking. Additionally, a distinct Raman peak at $1120 \mathrm{~cm}^{-1}$ supported the presence of $\mathrm{Si}-\mathrm{O}-\mathrm{Si}$ antisymmetric stretching present in composite material. $\mathrm{Pb}$ (II) ions adsorption studies were carried out at different temperature, $\mathrm{pH}$ and concentration of adsorbate and the filtrate was used for adsorption kinetics. Figure 3 represents the adsorption performance of PAS-GO, AS-GO, and $\mathrm{GO}$ for $\mathrm{Pb}(\mathrm{II})$ ions adsorption in aqueous solution. 


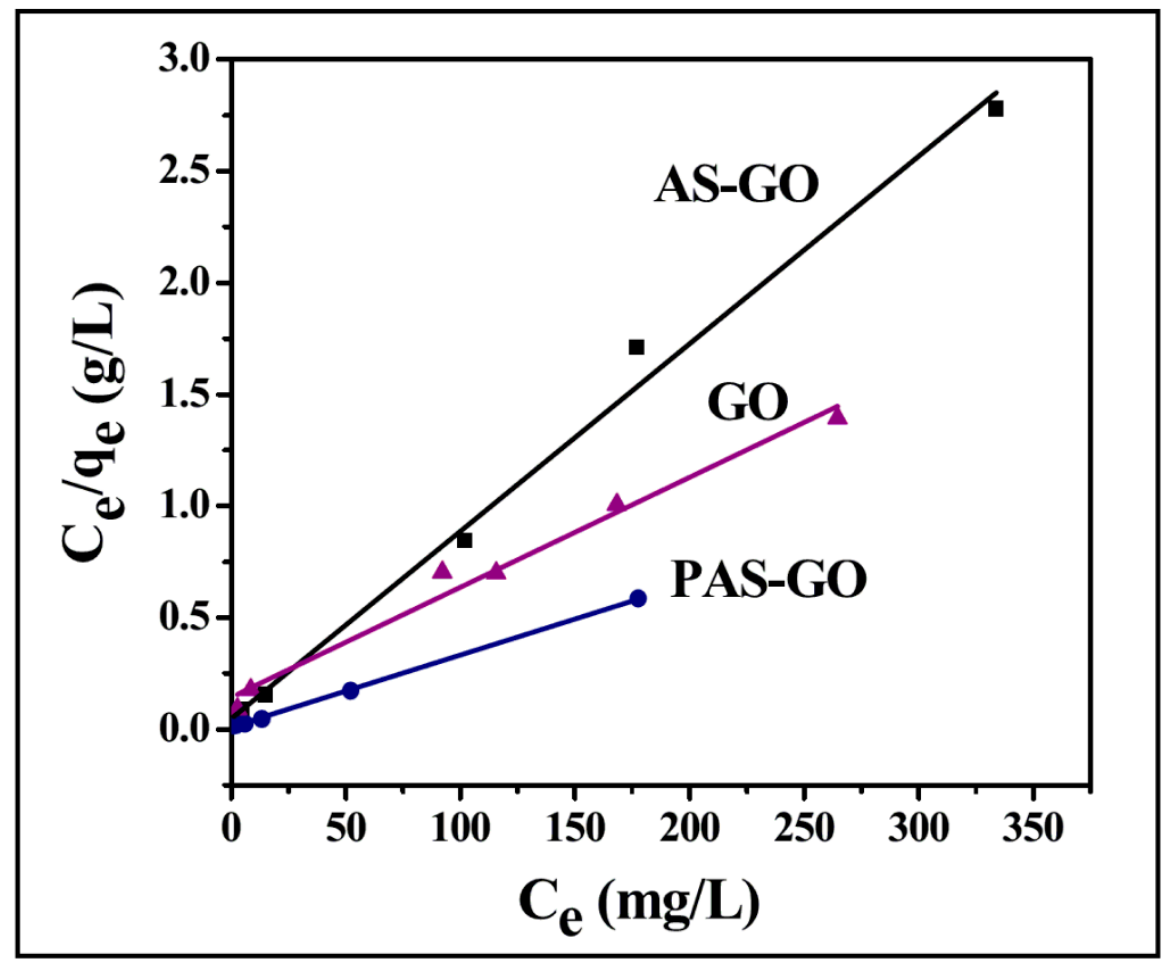

Figure 3. PAS-GO, AS-GO, and GO Langmuir isotherms for $\mathrm{Pb}(\mathrm{II})$ adsorption in aqueous solution at $303 \mathrm{~K}$ [193].

The Langmuir adsorption isotherms represent the maximum adsorption capacities for PAS-GO as compared to AS-GO and pure GO samples. The highest adsorption capacity of PAS-GO was $312.5 \mathrm{mg} / \mathrm{g}$, which was attributed due to the following factors:

(1) Multi-armed, three dimensional cross-linked functionality prevented GO nanosheets from aggregation, which may provide easier accessibility for trapping of foreign molecules.

(2) PAS oligomers chains, providing higher functionality/ binding sites in PAS-GO adsorbent, were supposed to be responsible for the higher adsorption of metal ions.

$\mathrm{pH}$ of the medium not only influences the adsorption capacities of the adsorbent but also facilitate selective metal ions adsorption [194-196]. Hence, $\mathrm{Pb}$ (II) ions adsorption at different $\mathrm{pH}$ from 2 to 6 were studied. As it is already discussed that in acidic media there is competition between $\mathrm{H}^{+}$and $\mathrm{Pb}$ (II) ions adsorption, hence, lower adsorption capacity for $\mathrm{Pb}$ (II) ions was observed at $\mathrm{pH}$ from 2 to 3 , while, as the $\mathrm{pH}$ of the medium increases to 4 , adsorption capacity of PAS-GO reached to $100 \%$ because at higher $\mathrm{pH}$, the effect of protonation becomes weak and negatively-charged hydroxyl and carboxylic acid functional groups leads higher $\mathrm{Pb}$ (II) ions adsorption. PAS-GO may be the best adsorbent for the removal of $\mathrm{Pb}$ (II) ions from acidic media ( $\mathrm{pH} 4.0-7.0)$ because these ions get precipitated in basic media $[189,190]$.

Langmuir, Freundlich, and Dubinin-Redushkevich adsorption isotherms were used to explain the adsorption mechanism of $\mathrm{Pb}$ (II) ions onto the surface of PAS-GO adsorbent. Langmuir and Freundlich isotherms are applicable for homogenous and heterogeneous surface adsorption respectively. Calculated results from adsorption isotherms revealed that the adsorption fitted well to Langmuir isotherm with a correlation coefficient $\left(R^{2}\right)$ values of $0.9996,0.9989$ and 0.9874 at $293 \mathrm{~K}, 303 \mathrm{~K}$ and $313 \mathrm{~K}$, respectively. Highest correlation coefficient and better fitted Langmuir isotherms confirmed the homogenous adsorption with all the adsorption sites of equal adsorption affinity. Maximum adsorption capacity increased from $200.00 \mathrm{mg} / \mathrm{g}$ to $344.80 \mathrm{mg} / \mathrm{g}$ as the temperature increased from $293 \mathrm{~K}$ to $313 \mathrm{~K}$ indicating endothermic adsorption process. 
$\mathrm{Xu}$ et al. reported the one step synthesis of polyacrylamide-grafted graphene (PAM-GO) composites via in situ radical polymerization by $300 \mathrm{kGy}$ doses $\gamma$-ray irradiation of the acrylamide monomer in an aqueous solution at room temperature, leading to GO single layer exfoliation into the PAM polymer [197]. The resulted PAM-GO adsorbent showed a $24.2 \%$ degree of grafting of PAM onto the graphene surface with a thickness of $2.59 \mathrm{~nm}$ that was a more powerful adsorbent for $\mathrm{Pb}(\mathrm{II})$ ions adsorption. Disappearance of XRD (X-ray diffraction spectroscopy) sharp peak from $2 \theta=10.7^{\circ}$ corresponding to 001 plane reflection from the XRD spectrum of PAM-GO indicated the complete exfoliation of GO sheets and intercalation of PAM chains into the GO layers. In the PAM-GO XPS spectrum, C1s peak at $284.4 \mathrm{eV}$ binding energy was attributed to the $\mathrm{C}-\mathrm{C}, \mathrm{C}=\mathrm{C}$ and $\mathrm{C}-\mathrm{H}$ bonds and the peak appeared at $288.4 \mathrm{eV}$ was correlated with the $\mathrm{O}=\mathrm{C}-\mathrm{N}$ bond of PAM $[163,198]$. Effect of contact time on the adsorption efficiency for PAM-GO adsorbent was studied for $45 \mathrm{mg} / \mathrm{L}$ as $\mathrm{Pb}$ (II) ions concentration at $\mathrm{pH}$ 6. The adsorption capacity of PAM-GO increased sharply within the first $20 \mathrm{~min}$. and reached at equilibrium within $30 \mathrm{~min}$. The short period of time for higher adsorption capacity highlights potential industrial applications of the PAM-GO adsorbent. Experimental value ( $440.4 \mathrm{mg} / \mathrm{g}$ ) calculated from pseudo-second-order kinetic model parameters for $\mathrm{Pb}$ (II) ions adsorption was similar to the calculated value $(458.7 \mathrm{mg} / \mathrm{g})$. The correlation coefficient $\left(\mathrm{R}^{2}=0.999\right)$ obtained from the pseudo-second-order kinetic model suggested that the adsorption process might be controlled by chemical adsorption involving valence forces through the sharing or exchange of electrons between the sorbent and sorbate. Langmuir and Freundlich isotherms comparison were studied for GO and $\mathrm{PAM}-\mathrm{GO}$ to examine the $\mathrm{Pb}(\mathrm{II})$ ions surface adsorption mechanism. The adsorption of $\mathrm{Pb}$ (II) for $\mathrm{GO}$ and PAM-GO was well fitted with the Langmuir isotherm model and higher $\mathrm{R}^{2}$ value, indicated specific homogeneous adsorption (i.e., with all the adsorption sites of equal adsorbate affinity) on GO and monolayer adsorption on the PAM-GO adsorbent $[199,200]$. The theoretical adsorption capacity of PAM-GO, determined from the Langmuir isotherm for $\mathrm{Pb}(\mathrm{II})$ was $819.67 \mathrm{mg} / \mathrm{g}$, which was 20 times higher than that of the GO nanosheets. Higher adsorption capacity of PAM-GO was attributed due to good water dispersibility and increased oxygen functionalities.

Yang et al. converted the peripheral carboxylic acid functional groups of reduced GO to amino groups using $N$-hydroxysuccinimide and 1,3-diaminopropane [201]. The free radical polymerization initiator was anchored at the surface of GO sheets and RGO-PAM polymer brushes were synthesized via in situ free radical polymerization of acrylamide. Staudenmaier method was used to prepare GO which includes the treatment of graphite with potassium chlorate in the presence of concentrated nitric and sulfuric acid. After the stipulated period of time, the reaction mixture was added to an excess of water followed by repeatedly washing till the filtrate neutrality. Free radical initiator was attached onto the surface of thermally reduced GO and used to graft PAM resulting RGO-PAM composites. Two FT-IR absorption peaks at $1384 \mathrm{~cm}^{-1}$ and $1446 \mathrm{~cm}^{-1}$ were attributed with the symmetric and asymmetric bending vibrations of methylene groups of an initiator attached onto the surface of reduced GO, respectively. XPS N1s binding energy absorption peak at $399.1 \mathrm{eV}$ indicated that surface grafting of a free radical initiator. Additionally, the absorption peak at $2242 \mathrm{~cm}^{-1}$ also confirmed the grafting of an initiator. Asymmetric C-H stretching vibration at $2925 \mathrm{~cm}^{-1}$ and $\mathrm{C}=\mathrm{O}$ stretching vibration at $1647 \mathrm{~cm}^{-1}$ were attributed with the grafting of PAM chains. $\mathrm{Pb}(\mathrm{II})$ ions were adsorbed onto the surface of RGO-PAM using dialysis and kinetics was studied since it gives deep knowledge insight the adsorption mechanism. Adsorption kinetics for $\mathrm{Pb}(\mathrm{II})$ ions adsorption was evaluated using Lagergren pseudo-first order (Equation (1)) and second-order (Equation (2)) modes:

$$
\begin{gathered}
\ln \left(\mathrm{q}_{\mathrm{e}}-\mathrm{q}_{\mathrm{t}}\right)=\ln \mathrm{q}_{\mathrm{e}}-\mathrm{k}_{1} \mathrm{t} \\
\frac{\mathrm{t}}{q_{t}}=\frac{1}{\left(k_{2} q_{e}^{2}\right)}+\frac{t}{q_{e}}
\end{gathered}
$$

where $q_{\mathrm{e}}$ and $q_{\mathrm{t}}$ are the amounts adsorbed in $\mathrm{mg} / \mathrm{g}$ at equilibrium and after time $\mathrm{t}$ in min., respectively; $\mathrm{k}_{1}$ and $\mathrm{k}_{2}$ are the adsorption rate constants for pseudo first- and second-order reactions respectively. 
The experimental results did not showed a linear fit with the calculated values; however, the $t / q_{t}$ plots showed good agreement with the pseudo second-order kinetics for $\mathrm{Pb}$ (II) ions adsorption. The correlation coefficients $\left(\mathrm{R}^{2}\right)$ for $\mathrm{Pb}$ (II) ion adsorption suggested that the pseudo second-order adsorption mechanism was dominant using RGO/PAM adsorbent. To better understand the adsorption mechanism, the Langmuir and Freundlich adsorption isotherms were studied and results are listed in Table 2. The $\mathrm{R}^{2}$ values for $\mathrm{Pb}(\mathrm{II})$ ions adsorption indicated that adsorption mechanism is well fitted with Langmuir isotherms and the maximum adsorption capacity of $\mathrm{Pb}$ (II) ions with $\mathrm{RGO}$ and RGO/PAM were found to be 500 and $1000 \mathrm{mg} / \mathrm{g}$, respectively.

Table 2. Langmuir and Freundlich adsorption results for $\mathrm{Pb}(\mathrm{II})$ onto the surface of RGO and RGO/PAM composite [201].

\begin{tabular}{ccccccccc}
\hline \multicolumn{4}{c}{ Langmuir Model } & \multicolumn{5}{c}{ Freundlich Model } \\
\hline Adsorbents & $\mathrm{q}_{\mathrm{m}}(\mathrm{mg} / \mathrm{g})$ & $\mathrm{K}_{\mathrm{L}}(\mathrm{L} / \mathrm{mg})$ & $\mathrm{R}^{2}$ & $\mathrm{RSD}$ & $\mathrm{K}_{\mathrm{F}}\left(\left(\mathrm{mg}^{1-\mathrm{n}} \mathrm{L}^{\mathrm{n}}\right) / \mathrm{g}\right)$ & $\mathrm{n}$ & $\mathrm{R}^{2}$ & $\mathrm{RSD}$ \\
RGO & 500 & 0.00149 & 0.989 & 0.0196 & 13.14 & 1.84 & 0.960 & 0.013 \\
PAM/GO & 1000 & 0.00137 & 0.987 & 0.0173 & 7.42 & 1.88 & 0.950 & 0.011 \\
\hline
\end{tabular}

Separation factor calculated from Langmuir isotherms for $\mathrm{Pb}(\mathrm{II})$ ions adsorption onto the surface of RGO-PAM was in the range of 0.313-0.901 indicating that the adsorption of $\mathrm{Pb}$ (II) ions was favorable and the adsorption capacity was highest as per literature reports [164]. The superior adsorption capacity of the RGO-PAM composite was attributed with the good dispersion of GO in an aqueous medium due to the introduction of highly functionalized PAM polymer. The adsorption capacity of the RGO-PAM composite was 2-3 times higher than the adsorption capacities of RGO and GO. Thermodynamic studies indicated the negative enthalpy changes, which were responsible for the spontaneous and exothermic adsorption of $\mathrm{Pb}$ (II) ions at different temperatures.

Yang et al. prepared ternary lignosulfonate-GO-polyaniline (LS-GO-PANI) nanocomposites via an in situ oxidative polymerization of aniline in the presence of lignosulfonate and GO and examined the effect of time, $\mathrm{pH}$ of the medium, adsorbent, and adsorbate concentration in an aqueous medium [72]. Scheme 4 represents the possible surface adsorption mechanism for $\mathrm{Pb}(\mathrm{II})$ ions from aqueous solution. LS is water soluble and has a large number of functional groups that are supposed to provide good adsorption interactions in the combination of GO and PANI. An air-tight oxidation method was used for GO preparation using sealed stainless steel autoclave [202]. In brief, expandable graphite, $\mathrm{KMnO}_{4}$ and sulfuric acid containing Teflon reactor was placed in stainless steel autoclave and heated at 110 ${ }^{\circ} \mathrm{C}$ for $2 \mathrm{~h}$. Resulted slurry was diluted and treated with $\mathrm{H}_{2} \mathrm{O}_{2}$ followed by repeatedly washing with dilute $\mathrm{HCl}$ and deionized water. LS-GO-PANI nanocomposite was prepared using suspension of GO, LS and aniline followed by the oxidative polymerization at $0{ }^{\circ} \mathrm{C}$ for $24 \mathrm{~h}$ using ammonium persulfate as an initiator. Due to enormous active edges and different surface functionalities, GO is compatible with polymer matrix and provide various nucleation sites for PANI chains anchoring. Moreover, $\pi-\pi$ interactions also favor surface polymerization of PANI onto the surface of GO [203-205]. Due to higher surface area, resulted LS-GO-PANI ternary composite showed higher adsorption capacity $(98.1 \mathrm{mg} / \mathrm{g})$ than GO-PANI ( $85.70 \mathrm{mg} / \mathrm{g}$ ) and virgin PANI (95.70) for $\mathrm{Pb}(\mathrm{II})$ ion adsorption. 


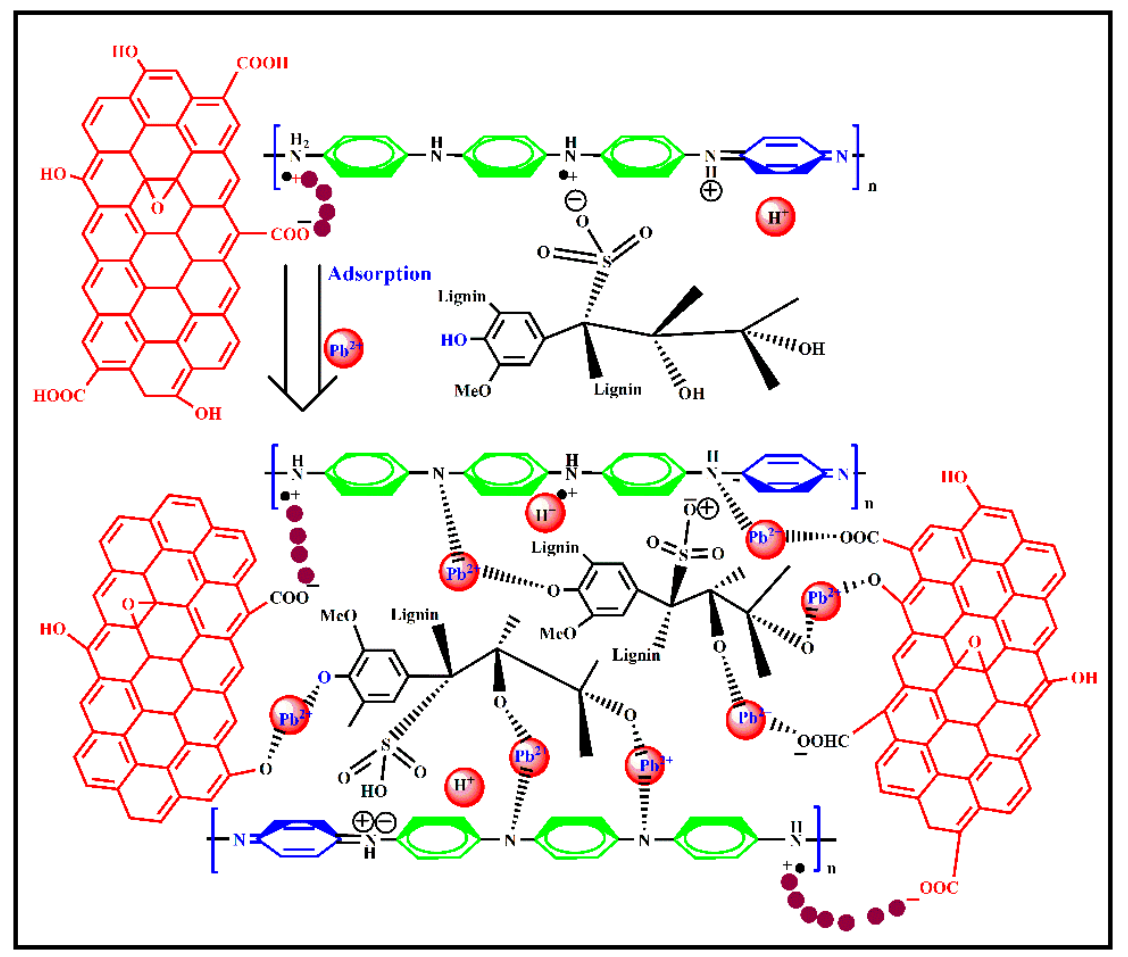

Scheme 4. Possible $\mathrm{Pb}(\mathrm{II})$ ion adsorption with LS-GO-PANI ternary composite adsorbent [72].

Figure 4 A represents the adsorption capacity $(Q)$ and adsorptivity $(q)$ effects with adsorption time for $1.6 \mathrm{~g} / \mathrm{L}$ ternary LS-GO-PANI adsorbent at $200 \mathrm{mg} / \mathrm{L} \mathrm{Pb}$ (II) ions initial concentration an initial $\mathrm{pH}$ of 5.0 at $30{ }^{\circ} \mathrm{C}$. Adsorption capacity and adsorptivity increased rapidly with time and reached 90.70 and $72.50 \%$ after $2 \mathrm{~h}$. After $4 \mathrm{~h}$, the adsorption capacity reached $98.30 \%$, which indicates the excellent adsorption capacity of LS-GO-PANI composite as compared with other adsorbents $[172,206]$. After reaching to saturation, there was a gradual decrease in the adsorption rate, which was correlated with the adsorption and desorption process at equilibrium onto the surface of the adsorbent. Figure 4B represents the effects of $\mathrm{pH}$ variation on the adsorption capacity using $1.6 \mathrm{~g} / \mathrm{L}$ ternary LS-GO-PANI adsorbent and $200 \mathrm{mg} / \mathrm{L}$ initial $\mathrm{Pb}$ (II) ions concentration. Figure $4 \mathrm{~B}$ represents the increasing adsorption efficiency of LS-GO-PANI adsorbent with the increasing $\mathrm{pH}$ from 2 to 5 . When the $\mathrm{pH}$ of the medium increased from 2 to 5, the adsorption efficiency of LS-GO-PANI composite ternary adsorbent increased because as the $\mathrm{pH}$ increases, the $\mathrm{H}^{+}$concentration decreases and other functional groups (carboxyl, epoxy, hydroxyl, and amino groups) get ionized, resulting in the higher adsorption for $\mathrm{Pb}(\mathrm{II})$ ions and reached to maximum $98.1 \mathrm{mg} / \mathrm{g}$ [207]. Hence, $\mathrm{pH} 5.0$ was set for the further studies for $\mathrm{Pb}$ (II) ions adsorptions. As shown in Figure 4C adsorption capacity decreased with LS-GO-PANI adsorbent contents while adsorptivity increased. Decreased adsorption capacity was attributed with the decreased surface area exposed to $\mathrm{Pb}(\mathrm{II})$ ions when the content of LS-GO-PANI adsorbent increased. Since, increasing adsorbent dosages for $\mathrm{Pb}(\mathrm{II})$ ions adsorption found to be invalid, hence, the effect of initial $\mathrm{Pb}$ (II) ions concentration was studied at fixed adsorbent dosage. Figure $4 \mathrm{D}$ represents the effect of sorbate concentration on the adsorption efficiency of LS-GO-PANI adsorbent. Adsorption efficiency of LS-GO-PANI adsorbent increased with the increased sorbate $\mathrm{Pb}(\mathrm{II})$ ions concentration. While adsorptivity initially increased then decreased after $100 \mathrm{mg} / \mathrm{g}$ sorbate concentration because on the increasing amount of sorbate there would not be enough adsorbent content to adsorb $\mathrm{Pb}(\mathrm{II})$ ions from the solution as LS-GO-PANI adsorbent gets saturation before $100 \%$ adsorption capacity. For $\mathrm{Pb}$ (II) ions adsorption, Langmuir adsorption isotherm was fitted well with higher coefficients of 0.9916 . Langmuir isotherms were correlated with the homogenous intermolecular forces between the sorbate and equally charged active sites of the adsorbent [172]. Higher adsorption capacity were attributed with the high 
surface area and large number of active functionalities which provided numerous nucleation sites for PANI growth and enhanced the surface for $\mathrm{Pb}(\mathrm{II})$ ions adsorption.
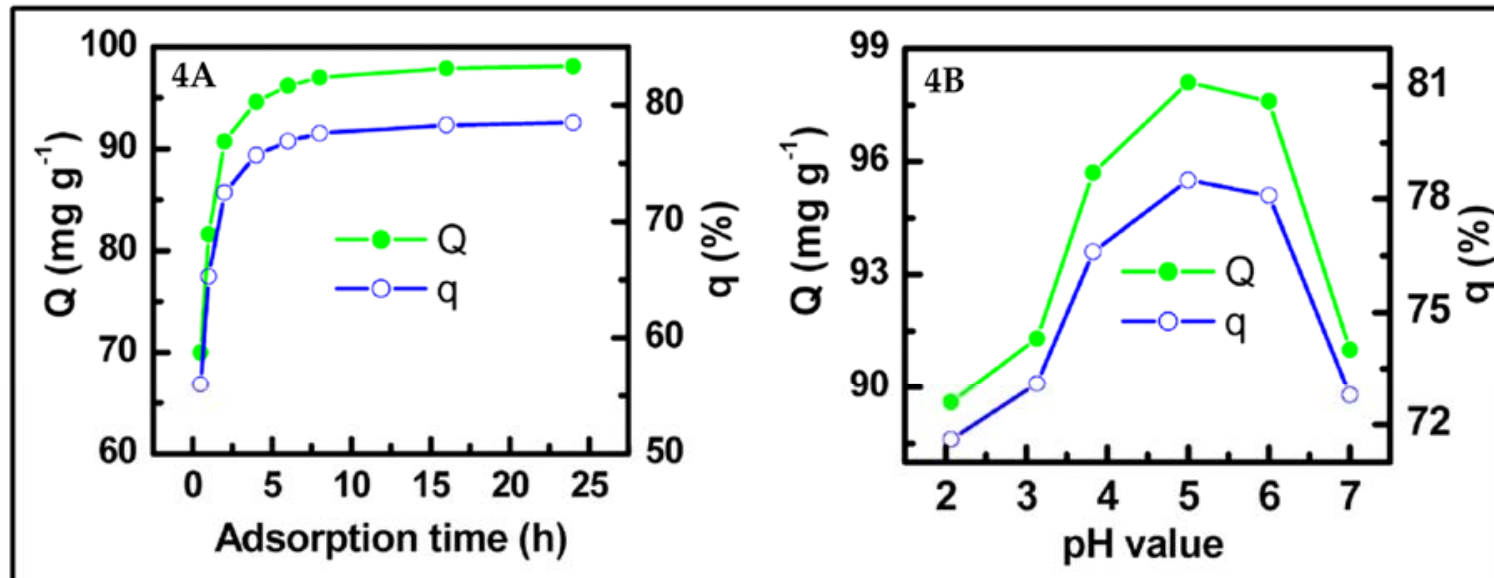

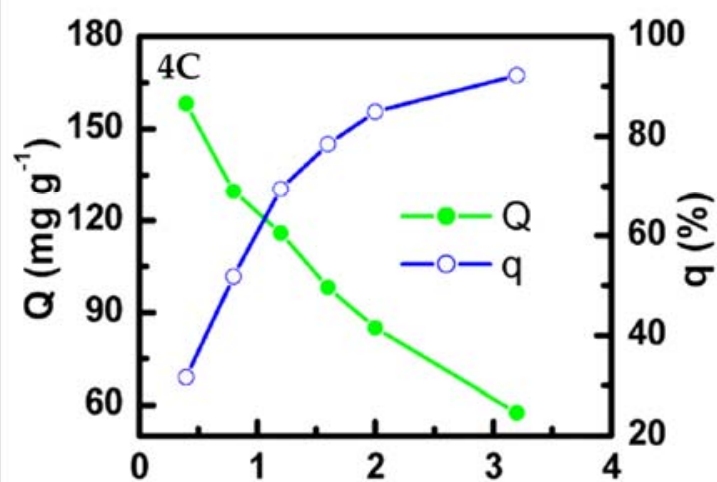

Absorbent concentration $\left(\mathrm{g} \mathrm{L}^{-1}\right)$

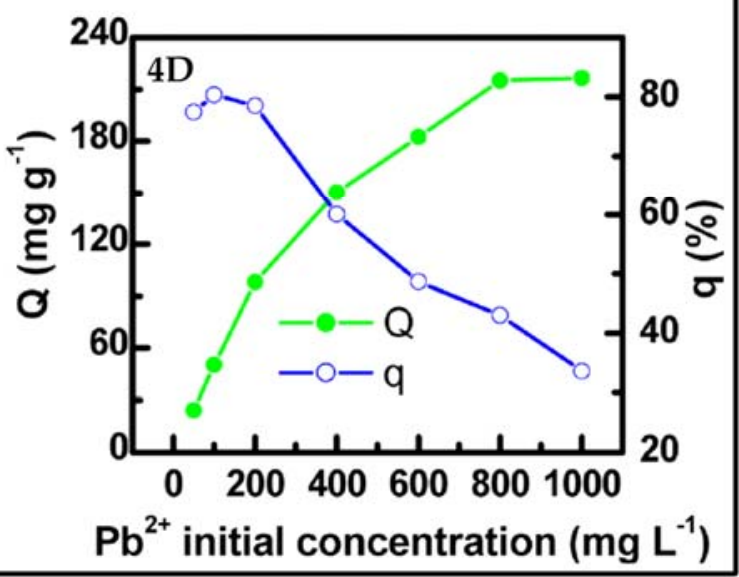

Figure 4. (A) Effect of contact time vs. adsorption capacity and adsorptivity of LS-GO-PANI adsorbent, (B) effect of $\mathrm{pH}$ on $\mathrm{Pb}$ (II) ions adsorption, (C) effect of adsorbent concentration at $200 \mathrm{mg} / \mathrm{L}$ initial $\mathrm{Pb}$ (II) ions concentration, and (D) effect of $\mathrm{Pb}(\mathrm{II})$ ions concentration [72].

\subsection{Removal of Lead using GO-Magnetite's}

Magnetitie's are the new class of materials which have drawn much attention in the current era specially in the wastewater treatment as the preparation of magnetite's is very simple and they can be easily separated using magnetic forces. Magnetite's are being widely used due to their low toxicity, environment friendly, and high adsorption ability [122,208]. Nickel ferrite based reduced graphene oxide (NFRGO) nanocomposite was reported by Lingamdinne et al. to optimized the independent variables viz. adsorbent dosage, solute concentration, and residence time for the removal of heavy metal $\mathrm{Pb}$ (II) ions from aqueous solution [209]. Ferrite's can be easily separated using external magnetic field and can be reused without any structural changes several times. Graphene based magnetite's not only separated/recovered easily but also shows higher absorption capacity $[208,210,211]$. For the preparation of NFRGO, hydrazine hydrate was added to the GO dispersion as prepared by Hummer's method [212,213]. At $\mathrm{pH} \geq 12$ nickel nitrate and ferric nitrate solutions in 1:2 molar ratio were added to the above solution in an inert atmosphere and the solution was stirred for $5 \mathrm{~h}$ at $120^{\circ} \mathrm{C}$ (Scheme 5). Resulted black precipitate was cooled to room temperature and repeatedly washed with deionized water and ethanol to remove the impurities. NFRGO was separated by external magnate and dried under vacuum for 24 at $60^{\circ} \mathrm{C}$. As prepared NFRGO was characterized using XRD, XPS, and Raman spectroscopy. XRD peaks at $2 \theta=18.28^{\circ}$ and $40^{\circ}$ were observed with correspond to RGO [214,215]. Presence of $2 \theta$ at $30.43^{\circ}, 35.60^{\circ}, 43.26^{\circ}, 57.32^{\circ}$ and $62.70^{\circ}$ confirmed the formation of spinel nickel 
ferrite onto GO surface [216,217]. Shifting of XPS peaks from $532.4 \mathrm{eV}$ to lower range at $530.3 \mathrm{eV}$ confirmed the reduction of GO to RGO. Additionally, the presence of $\mathrm{O}(1 \mathrm{~s})$ at $530.3, \mathrm{Fe}(2 \mathrm{P})$ at $711.00 \mathrm{eV}$ and $\mathrm{Ni}(2 \mathrm{P})$ at $855.00 \mathrm{eV}$ peaks confirmed the formation of NFRGO. In Raman spectrum, $\mathrm{G}$ band stands for first-order scattering of $\mathrm{E}_{2 \mathrm{~g}}$ mode for $\mathrm{sp}^{2}$ carbon atoms whereas $\mathrm{D}$ band is correspond with the vibrations of $\mathrm{sp}^{3}$ carbon atoms. Shifting of D band from $1358 \mathrm{~cm}^{-1}$ to $1303 \mathrm{~cm}^{-1}$ and $\mathrm{G}$ band from $1606 \mathrm{~cm}^{-1}$ to lower shift at $1591 \mathrm{~cm}^{-1}$ indicated the reduction of GO. Enhanced intensity ratio $\left(\mathrm{I}_{\mathrm{D}} / \mathrm{I}_{\mathrm{G}}\right)$ from $0.96(\mathrm{GO})$ to 1.094 (NFRGO) confirmed the reduction of GO. $167.26 \mathrm{~m}^{2} / \mathrm{g}$ surface area was measured using Brunauer-Emmett and Teller (BET) method. Pore volume, $0.24 \mathrm{~cm}^{3} / \mathrm{g}$ and $5.59 \mathrm{~nm}$ pore diameter indicated the formation of meso-porous nano-crystalline NFRGO composite adsorbent.
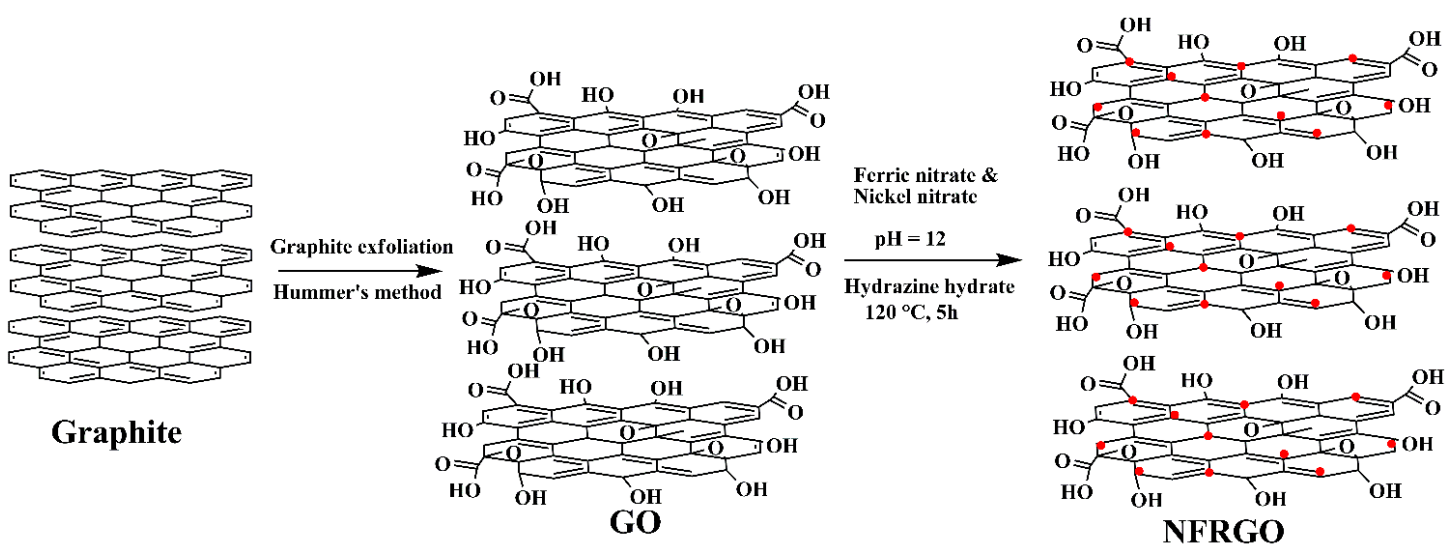

Scheme 5. Schematic representation of NFRGO preparation [209].

Adsorption experiments were optimized using different independent variables such as adsorbent dosage, solute concentration and residence time and average values were considered for further studies. All these factors had an interactive consequence when used in combinations. For example, on increasing adsorbent dosage from $250 \mathrm{mg} / \mathrm{L}$ to $550 \mathrm{mg} / \mathrm{L}$, a significant enhancement in adsorption efficiency from 80 to $90 \%$ was observed whereas adsorption efficiency decreased on increasing the initial solution concentration. Trend was correlated with the accessibility of more vacant active sites due to increased surface area. Reduction in ions removal efficiency was observed on increasing solution concentration with the saturation of active sites of adsorbent whereas there was no significant effect of adsorbent's residual time. On increasing the adsorbent dosage from $250 \mathrm{mg} / \mathrm{L}$ to $550 \mathrm{mg} / \mathrm{L}$, there was a significant enhancement in $\mathrm{Pb}$ (II) ions removal efficiency from 87 to $98 \%$. No significant increase on further adsorbent dosage increasing was correlated with the dominance of the repulsive forces in the functional groups. Comparative results of three variables viz. adsorbent dosage, residual time and solution concentration have been depicted in Figure 5. Based on the results of experimental runs, independent variables $18.38 \mathrm{mg} / \mathrm{L}$ initial solution concentration, $550 \mathrm{mg} / \mathrm{L}$ adsorbent dosage and 83 min adsorbent residual time were optimized which not only may be helpful to reduce the cost of operating treatment process of an industry but also may also reduce the time in achieving the desired performance. 


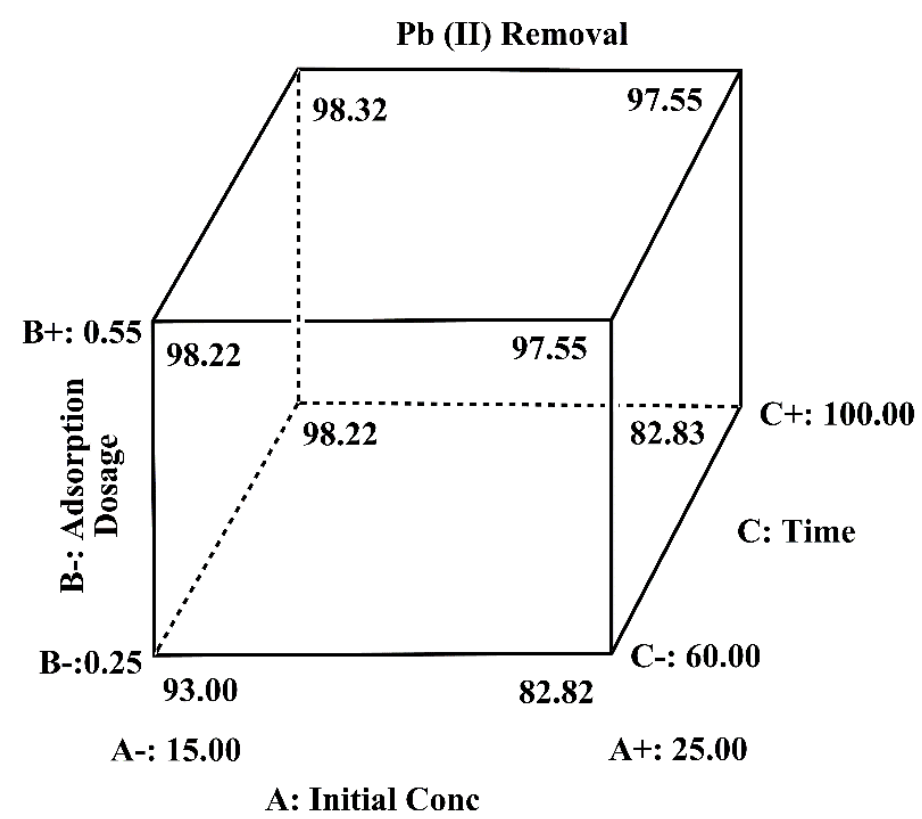

Figure 5. Cubic representation of independent variables response [209].

Zhang et al. reported the preparation of magnetic cobalt ferrite-reduced graphene oxide $\left(\mathrm{CoFe}_{2} \mathrm{O}_{4}-\mathrm{rGO}\right)$ nanocomposite to absorb the $\mathrm{Pb}$ (II) ions from aqueous solution [218]. $\mathrm{CoFe}_{2} \mathrm{O}_{4}-\mathrm{rGO}$ nanocomposite was prepared as reported in literature and used for metal ions adsorption $[219,220]$. In brief, iron(III) nitrate and cobalt (III) nitrate solutions were drop wise added to the ultrasonicated GO suspension under vigorous stirring. $\mathrm{pH} 12$ was adjusted using $5 \% \mathrm{NaOH}$ aqueous solution and hydrazine hydrate solution was added slowly to GO suspension. Reaction mixture was stirred for $5 \mathrm{~h}$ at $80{ }^{\circ} \mathrm{C}$ and cooled to room temperature. Purification was carried out using magnet followed by repeatedly washing with deionized water and absolute ethanol and dried at $50{ }^{\circ} \mathrm{C}$ for $24 \mathrm{~h}$ under vacuum. $\mathrm{CoFe}_{2} \mathrm{O}_{4}$-rGO was characterized with the help of XRD where the $\mathrm{CoFe}_{2} \mathrm{O}_{4}$ nanoparticles were found in correspondent with the previous report and the presence of XRD peak $2 \theta$ at $26.5^{\circ}$ confirmed that $\mathrm{CoFe}_{2} \mathrm{O}_{4}$-rGO was well crystallized. Low zeta potential indicated the availability of entire negatively-charged functional groups environment from $\mathrm{pH} 4$ to 10 for the better adsorption of heavy metal ions and $\mathrm{CoFe}_{2} \mathrm{O}_{4}$-rGO was found to be well dispersed in water pertaining a black suspension in aqueous solution.

Adsorption analysis involved the use of different dosage of $\mathrm{CoFe}_{2} \mathrm{O}_{4}-\mathrm{rGO}$ adsorbent and $8 \mathrm{mg} / \mathrm{L}$ was optimized to study the $\mathrm{Pb}(\mathrm{II})$ ions adsorption at various $\mathrm{pH}$ from lead (II) nitrate solution $(20 \mathrm{~g} / \mathrm{L})$. From the results, it is clear that the adsorption of $\mathrm{Pb}(\mathrm{II})$ ions was very sensitive to $\mathrm{pH}$ variations. At low $\mathrm{pH}$, low adsorption efficiency was attributed due to the increased repulsive forces between the positively-charged functional groups of adsorbent and positively-charged $\mathrm{Pb}(\mathrm{II})$ ions and the precipitation of $\mathrm{Pb}(\mathrm{II})$ ions as $[\mathrm{Pb}(\mathrm{OH})],\left[\mathrm{Pb}(\mathrm{OH})_{2}\right],\left[\mathrm{Pb}(\mathrm{OH})_{3}\right]^{-},\left[\mathrm{Pb}_{3}(\mathrm{OH})_{4}\right]^{2+}\left[\mathrm{Pb}_{2}(\mathrm{OH})\right]^{2+}$ $\left[\mathrm{Pb}_{6}(\mathrm{OH})_{8}\right]^{4+}$, and $\left[\mathrm{Pb}_{4}(\mathrm{OH})_{4}\right]^{4+}[164,221,222]$. Increase adsorption efficiency over $\mathrm{pH} 4$ was attributed with the increased attractive forces between the positively-charged functional groups of adsorbent and positively-charged $\mathrm{Pb}(\mathrm{II})$ ions and was found to be highest as $87 \%$ at $5.3 \mathrm{pH}$. The adsorption kinetics was analyzed using pseudo-first and second-order kinetic models. The adsorption of $\mathrm{Pb}$ (II) ions by $\mathrm{CoFe}_{2} \mathrm{O}_{4}$-rGO reached equilibrium in $80 \mathrm{~min}$. Pseudo-second order model was found to be well fitted with the $\mathrm{R}^{2}$ value of 0.9934 suggesting chemisorption adsorption process and the calculated value was found to be $122.2 \mathrm{mg} / \mathrm{g}$. Adsorption isotherms were analyzed using Langmuir and Freundlich equations. Langmuir isotherms were found to be well fitted with the experimental data which indicated the monolayers adsorption of $\mathrm{Pb}$ (II) ions onto the surface of $\mathrm{CoFe}_{2} \mathrm{O}_{4}$-rGO adsorbent.

Fan et al. prepared magnetic ternary composites of chitosan, $\mathrm{Fe}_{3} \mathrm{O}_{4}$, and $\mathrm{GO}$ for the effective and selective removal of $\mathrm{Pb}(\mathrm{II})$ ions from aqueous solution [223]. To ultrasonicated $\mathrm{GO}$ solution, reagents 
1-ethyl-3(3-hydroxyethylaminoprophy) carbondiimide hydrochloride and N-hydroxylsuccinimimde were added at $\mathrm{pH}$ to activate carboxylic functionalities of GO. Magnetic chitosan and activated GO was suspended using ultrasonication for $10 \mathrm{~min}$ and stirred for $2 \mathrm{~h}$ at $60^{\circ} \mathrm{C}$. The precipitate was washed with $\mathrm{NaOH}$ and then with water repeatedly until the $\mathrm{pH} 7$ was obtained. MCGO product was collected using magnet and dried under vacuum at $50^{\circ} \mathrm{C}$. The magnetic fluid was coated onto chitosan to accelerate the separation through an improved surface area and reduce the dose requirement for the adsorption of $\mathrm{Pb}(\mathrm{II})$ ions. The adsorption amounts and adsorption rates were calculated from the concentration difference of the solution used before and after the adsorption process using following equations:

$$
\begin{gathered}
Q=\frac{\left(\mathrm{C}_{0}-\mathrm{C}_{e}\right) \mathrm{V}}{\mathrm{W}} \\
E=\frac{\mathrm{C}_{0}-\mathrm{C}_{0}}{\mathrm{C}_{0}} \times 100 \%
\end{gathered}
$$

where $C_{0}$ and $C_{e}$ are the initial and the equilibrium concentrations of metal ions in $\mathrm{mL} / \mathrm{L}$, respectively; $\mathrm{W}$ is the amount of an adsorbent used, in grams; and V is the volume of metal ion solution in liter. Since, the adsorption is very sensitive to $\mathrm{pH}$ variations, adsorption capacity of MCGO was determined at varying $\mathrm{pH}$ from 1.0 to 7.0. At low $\mathrm{pH}$, excessive competitive $\mathrm{H}^{+}$ions concentration inhibits the adsorption of $\mathrm{Pb}(\mathrm{II})$ ions and usually adsorption of heavy metal ions do not occur at low $\mathrm{pH}$. $\mathrm{Pb}$ (II) ions adsorption capacity increased with the increasing $\mathrm{pH}$ from 1-5 and was measured $50.23 \mathrm{mg} / \mathrm{g}$ at $\mathrm{pH}$ 5. In acidic media, the slight decrease in uptake was attributed to amino group protonation, which may hinder complex formation.

$\mathrm{Pb}$ (II) ions adsorption onto MCGO was obtained maximum within first $30 \mathrm{~min}$. and no significant alteration was observed after $1 \mathrm{~h}$ which indicated that optimum adsorption time for $\mathrm{Pb}$ (II) ions. The initial higher sorption within $60 \mathrm{~min}$. was attributed to high surface reactivity of MCGO due to sufficient number of exposed active sites followed by the large surface area, which decreased later on due to a decrease in the number of bonding sites on the surface of the adsorbent and aggregation between particulates. Langmuir and Freundlich isotherms are the fundamental and most frequently used adsorption isotherms to describe the adsorption phenomenon and behavior of metal ions onto the surfaces. The maximum adsorption capacity of MCGO determined from the Langmuir isotherm was found to be $82.10 \mathrm{mg} / \mathrm{g}$, which was almost similar with the calculated value of $76.94 \mathrm{mg} / \mathrm{g}$ for monolayer chelation adsorption. Higher adsorption capacity for $\mathrm{Pb}(\mathrm{II})$ ions when compared with other adsorbents were attributed with the additional interactions of axial hydroxyl and amino functional groups with metal ions. For the possibility of regeneration and reusability of MCGO, experimentally desorption efficiency was found to be $90.3 \%$ and $90.1 \%$ at $\mathrm{pH} 1$ and 2, respectively, indicating that adsorbed metal ions could be removed efficiently by desorption from the adsorbent surface. Adsorption percentage almost remained steady in the first four regeneration cycles and then decreased to $75 \%$ after fifth regeneration cycles. Hence, regeneration and reusability indicated that biodegradable and biocompatible MCGO has long term stability for the adsorption of $\mathrm{Pb}(\mathrm{II})$ ions.

A composite of hydrated manganese oxide and GO (HMO-GO) with excellent settling ability ( $<2 \mathrm{~min}$ ) was fabricated by in-situ growth of nanosized hydrated manganese oxide (HMO) onto the GO nanosheet surface [224]. Typically, GO was suspended into $\mathrm{MnCl}_{2}$ solution at $\mathrm{pH} 7$ for $24 \mathrm{~h}$ at room temperature followed by centrifugation to obtained $\mathrm{Mn}$ (II)-GO which was further added to $\mathrm{NaClO}-\mathrm{NaOH}$ solution at the alkalinity of $5 \%$ and active chlorine of $6 \%$. The mixed solution was stirred for $24 \mathrm{~h}$ to oxidize $\mathrm{Mn}(\mathrm{II})$ to $\mathrm{Mn}(\mathrm{IV})$. Finally, the solution was centrifuged and solid was repeatedly washed with $\mathrm{HCl}$ and deionized water untill neutral $\mathrm{pH}$ and freeze dried under vacuum. HMO grafted GO i.e., HMO-GO adsorbent substructure revealed that electron dense single grain HMO nanoparticles were uniformly distributed onto the GO surface. To increase the oxygenated abundance onto the GO surface, polymer or surfactants as stabilizers were dispersed using similar approaches $[175,225]$. Adsorption behavior of HMO-GO composite and GO as an adsorbent were compared at $\mathrm{pH}$ from 2.5 to 6.7. The adsorption capacity of HMO-GO and GO increased with increasing $\mathrm{pH}$ of the medium 
because at higher $\mathrm{pH}$, deprotonation increases, which results more negative active sites to adsorb positively-charged $\mathrm{Pd}(\mathrm{II})$ ions. A sharp decrease in adsorption capacity in strong acidic media indicated the regeneration possibilities of HMO-GO adsorbent for reuse. The leaching of Mn from HMO-GO was negligible during the adsorption experiment over the entire $\mathrm{pH}$ range.

Selective adsorption of $\mathrm{Pb}$ (II) ions in presence of $\mathrm{Ca}$ (II) and $\mathrm{Mg}$ (II) co-existing ubiquitous versatile alkaline earth metal cations onto the surface of HMO-GO was compared with that of GO. Presence of $\mathrm{Ca}(\mathrm{II})$ and $\mathrm{Mg}$ (II) cations (concentration of $\mathrm{Ca}(\mathrm{II}), \mathrm{Mg}(\mathrm{II}) / \mathrm{Pb}(\mathrm{II})=50$ ) do not affected the selective adsorption of $\mathrm{Pb}(\mathrm{II})$ ions by $\mathrm{HMO}-\mathrm{GO}$ adsorbent whereas a significant reduction in the adsorption capacity of $\mathrm{GO}$ was observed. Selective $\mathrm{Pb}$ (II) ions adsorption by HMO-GO was attributed with the specific, complex adsorption process by nanostructured homogenous distribution HMO onto the surface of GO [226]. Reduced desorption of $\mathrm{Pb}$ (II) ions onto GO was attributed with the nonspecific, electrostatic attraction of oxygenated functional groups and greatly affected due to the presence of $\mathrm{Ca}(\mathrm{II})$ and $\mathrm{Mg}(\mathrm{II})$ cations.

Due to lower $\Delta G_{\text {hydration }}^{0}(\mathrm{Ca}(\mathrm{II})=-1656 \mathrm{~kJ} / \mathrm{mol}$, than $\mathrm{Mg}(\mathrm{II})=-2049 \mathrm{~kJ} / \mathrm{mol})$ and greater ion exchange ability, $\mathrm{Ca}$ (II) had greater influenced on the adsorption of $\mathrm{Pb}$ (II) ions onto GO surface [227]. Higher distribution coefficient of $\mathrm{HMO}-\mathrm{GO}$ further indicated the selective adsorption of $\mathrm{Pb}$ (II) ions which slightly influenced due to humic acid presence which forms strong complexes with $\mathrm{Pb}$ (II) ions or other heavy metal ions by $\pi-\pi$ interactions [67]. A 3-4 time higher $\mathrm{Pb}(\mathrm{II})$ ion adsorption by HMO-GO than GO and bulky HMO in presence of $500 \mathrm{mg} / \mathrm{L} \mathrm{Ca(II)} \mathrm{was} \mathrm{attributed} \mathrm{with} \mathrm{the} \mathrm{homogenously}$ distributed nanosized HMO. The HMO-GO and GO adsorption isotherms for $\mathrm{Pb}(\mathrm{II})$ at $\mathrm{pH} 5$ in the absence and presence of $\mathrm{Ca}$ (II) were investigated using the Freundlich and the Langmuir models. The higher correlation coefficients of the Freundlich model than the Langmuir model for HMO-GO suggested a heterogeneous chemisorption process through inner-sphere complexation, whereas, opposite results were obtained for GO, suggesting monolayer adsorption on the surface through simple ion exchange method. The experimentally obtained sorption capacity of $\mathrm{Pb}$ (II) for HMO-GO was $553.6 \mathrm{mg} / \mathrm{g}$, which was higher than that observed for any other Mn-based adsorbent [224].

\section{Conclusions and future perspective}

Graphene based nanoadsorbents have been proven to play the vital role in the selective adsorption of heavy metal ions, such as $\mathrm{Pb}(\mathrm{II})$, from wastewater. The selective recovery and reuse of valuable adsorbents and pollutants are the important challenges for the adsorption technology using nanoadsorbents with favorable structures, morphology, superior adsorption capacities, and ease of separation. Graphene is always thanked for its unique property of functionalization, used to alter its properties and, consequently, its applications. This review exploited recently-developed graphene-based novel nanoadsorbents for the effective and selective removal of $\mathrm{Pb}$ (II) ions from wastewaters. In addition to the various own functionalities, GO was further surface modified with the negatively-charged functional groups to enhance the selective and effective $\mathrm{Pb}$ (II) ion adsorption from wastewaters. Due to wide varieties of surface functional groups, high surface area, and a preponderance of exposed edges planes, GO exhibited remarkable superior adsorption of $\mathrm{Pb}(\mathrm{II})$ ions. In addition, GO composites with ion scavengers (for example, EDTA), metal nanoparticles, magnetites, polymers, and aerogels have been reviewed for the adsorption of $\mathrm{Pb}$ (II) ions under the influence of temperature, $\mathrm{pH}$ of the medium, adsorbate, and sorbent loadings, etc., and exhibited superior adsorption than pristine $\mathrm{GO}$ for $\mathrm{Pb}$ (II) ion adsorption from an aqueous solution. One of the major advantages revealed by the graphene-based nanoadsorbents is the recovery of adsorbents and adsorbates even after a series of life cycles. Although simple and effective routes for GO-based nanoadsorbents with high surface area and pore size for superior adsorption of heavy metal ions are still in demand, graphene-based nanoadsorbents have proven their potential adsorbability for the expediency of mankind and the environment.

Author Contributions: S.H.H., M.K. put forwarded the idea and prepared the manuscript. J.S.C. and S.H.H. has edited and approved the manuscript. 
Funding: This study was supported by the Basic Science Research Program through the National Research Foundation of Korea (NRF) funded by The Ministry of Science, ICT and Future Planning (2019R1A2B5B02069683).

Conflicts of Interest: The authors declare no conflict of interest.

\section{References}

1. Rao, Z.; Feng, K.; Tang, B.; Wu, P. Surface decoration of amino-functionalized metal-organic framework/graphene oxide composite onto polydopamine-coated membrane substrate for highly efficient heavy metal removal. ACS Appl. Mater. Interfaces 2017, 9, 2594-2605. [CrossRef] [PubMed]

2. Nriagu, J.O.; Pacyna, J.M. Quantitative assessment of worldwide contamination of air, water and soils by trace metals. Nature 1988, 333, 134-139. [CrossRef] [PubMed]

3. Afkhami, A.; Saber-Tehrani, M.; Bagheri, H. Simultaneous removal of heavy metal ions in wastewater samples using nano-alumina modified with 2,4-dinitrophenylhydrazine. J. Hazard. Mater. 2010, 181, 836-844. [CrossRef] [PubMed]

4. Ahluwalia, S.S.; Goyal, D. Microbial and plant derived biomass for removal of heavy metals from wastewater. Bioresour Technol. 2007, 98, 2243-2257. [CrossRef] [PubMed]

5. Shannon, M.A.; Bohn, P.W.; Elimelech, M.; Georgiadis, J.G.; Mariñas, B.J.; Mayes, A.M. Science and technology for water purification in the coming decades. Nature 2008, 452, 301-310. [CrossRef]

6. Vörösmarty, C.J.; McIntyre, P.B.; Gessner, M.O.; Dudgeon, D.; Prusevich, A.; Green, P.; Glidden, S.; Bunn, S.E.; Sullivan, C.A.; Liermann, C.R.; et al. Global threats to human water security and river biodiversity. Nature 2010, 467, 555-561.

7. Cesaro, A.; Naddeo, V.; Belgiorno, V. Wastewater treatment by combination of advanced oxidation processes and conventional biological systems. J. Bioremed. Biodeg. 2013, 4, 8.

8. Fu, F.; Wang, Q. Removal of heavy metal ions from wastewaters: A review. J. Environ. Manag. 2011, 92, 407-418. [CrossRef]

9. Chen, C.; Wang, X. Adsorption of $\mathrm{Ni}(\mathrm{II})$ from aqueous solution using oxidized multiwall carbon nanotubes. Ind. Eng. Chem. Res. 2006, 45, 9144-9149. [CrossRef]

10. Cervantes, C.; Jesus, C.G.; Silvia, D.; Felix, G.C.; Herminia, L.T.; Carlos, T.G.J.; Rafael, M.S. Interactions of chromium with microorganism and plants. FEMS Microbiol. Rev. 2001, 25, 335-347. [CrossRef]

11. Teow, Y.; Asharani, P.V.; Hande, M.P.; Valiyaveettil, S. Health impact and safety of engineered nanomaterials. Chem. Commun. 2011, 47, 7025-7038. [CrossRef] [PubMed]

12. Järup, L. Hazards of heavy metal contamination. Br. Med. Bull. 2003, 68, 167-182. [CrossRef] [PubMed]

13. Gopalakrishnan, A.; Krishnan, R.; Thangavel, S.; Venugopal, G.; Kim, S.-J. Removal of heavy metal ions from pharma-effluents using graphene-oxide nanosorbents and study of their adsorption kinetics. J. Ind. Eng. Chem. 2015, 30, 14-19. [CrossRef]

14. Draszawka-Bołzan, B. Effect of heavy metals on living organisms. World Sc.News 2014, 5, 26-34.

15. Tirtom, V.N.; Dinçer, A.; Becerik, S.; Aydemir, T.; Çelik, A. Removal of lead(II) ions from aqueous solution by using crosslinked chitosan-clay beads. Desalin. Water Treat. 2012, 39, 76-82. [CrossRef]

16. Gollavelli, G.; Chang, C.-C.; Ling, Y.-C. Facile synthesis of smart magnetic graphene for safe drinking water: heavy metal removal and disinfection control. ACS Sustain. Chem. Eng. 2013, 1, 462-472. [CrossRef]

17. World Health Organization. Guidelines for Drinking Water, Quality; World Health Organization: Geneva, Switzerland, 1984.

18. Arbabi, M.; Hemati, S.; Amiri, M. Removal of lead ions from industrial wastewater: A review of removal methods. Int. J. Epidemiol. Res. 2015, 2, 105-109.

19. Zhu, H.; Xu, Y.; Liu, A.; Kong, N.; Shan, F.; Yang, W.; Barrow, C.J.; Liu, J. Graphene nanodots-encaged porous gold electrode fabricated via ion beam sputtering deposition for electrochemical analysis of heavy metal ions. Sens. Actuar. B 2015, 206, 592-600. [CrossRef]

20. Rashed, M. Lead removal from contaminated water using mineral adsorbents. Environmentalist 2001, 21, 187-195. [CrossRef]

21. Kaushal, A.; Singh, S.K. Adsorption phenomenon and its application in removal of lead from waste water: A review. Int. J. Hydrog. 2017, 1, 1-8. [CrossRef] 
22. Santhosh, C.; Nivetha, R.; Kollu, P.; Srivastava, V.; Sillanpää, M.; Grace, A.N.; Bhatnagar, A. Removal of cationic and anionic heavy metals from water by 1D and 2D-carbon structures decorated with magnetic nanoparticles. Sci. Rep. 2017, 7, 14107. [CrossRef] [PubMed]

23. Wang, G.; Zhang, S.; Yao, P.; Chen, Y.; Xu, X.; Li, T.; Gong, G. Removal of Pb(II) from aqueous solutions by Phytolacca americana L. biomass as a low cost biosorbent. Arabian J. Chem. 2018, 11, 99-110. [CrossRef]

24. Luzardo, F.H.M.; Velasco, F.G.; Correia, I.K.S.; Silva, P.M.S.; Salay, L.C. Removal of lead ions from water using a resin of mimosa tannin and carbon nanotubes. Environ. Technol. Innov. 2017, 7, 219-228. [CrossRef]

25. Flora, G.; Gupta, D.; Tiwari, A. Toxicity of lead: A review with recent updates. Interdiscip. Toxicol. 2012, 5, 47-58. [CrossRef] [PubMed]

26. Zhao, G.; Ren, X.; Gao, X.; Tan, X.; Li, J.; Chen, C.; Huang, Y.; Wang, X. Removal of Pb(II) ions from aqueous solutions on few-layered graphene oxide nanosheets. Dalton Trans. 2011, 40, 10945-10952. [CrossRef] [PubMed]

27. Rosillo-Lopez, M.; Salzmann, C.G. Highly efficient heavy-metal extraction from water with carboxylated graphene nanoflakes. RSC Adv. 2018, 8, 11043-11050. [CrossRef]

28. Zhang, Y.; Zhang, S.; Chung, T.-S. Nanometric graphene oxide framework membranes with enhanced heavy metal removal via nanofiltration. Environ. Sci. Technol. 2015, 49, 10235-10242. [CrossRef]

29. Khulbe, K.C.; Matsuura, T. Removal of heavy metals and pollutants by membrane adsorption techniques. Appl. Water Sci. 2018, 8, 19. [CrossRef]

30. Shimizu, Y.; Okuno, Y.I.; Uryu, K.; Ohtsubo, S.; Watanabe, A. Filtration characteristics of hollow fiber microfltration membranes used in membrane bioreactor for domestic wastewater treatment. Water Res. 1996, 30, 2385-2392. [CrossRef]

31. Sulyman, M.; Namiesnik, J.; Gierak, A. Low-cost adsorbents derived from agricultural by-products/wastes for enhancing contaminant uptakes from wastewater: A review. Pol. J. Environ. Stud. 2017, 26, 479-510. [CrossRef]

32. Gupta, V.K.; Nayak, A.; Agarwal, S. Bioadsorbents for remediation of heavy metals: Current status and their future prospects. Environ. Eng. Res. 2015, 20,1-18. [CrossRef]

33. Wang, X.; Guo, Y.; Yang, L.; Han, M.; Zhao, J.; Cheng, X. Nanomaterials as sorbents to remove heavy metal ions in wastewater treatment. J. Environ. Anal. Toxicol. 2012, 2, 1-5. [CrossRef]

34. Bhatluri, K.K.; Manna, M.S.; Ghoshal, A.K.; Saha, P. Supported liquid membrane based removal of lead(II) and cadmium(II) from mixed feed: Conversion to solid waste by precipitation. J. Hazard. Mater. 2015, 299, 504-512. [CrossRef] [PubMed]

35. Dabrowski, A.; Hubicki, Z.; Podkoscielny, P.; Robens, E. Selective removal of the heavy metal ions from waters and industrial wastewaters by ion-exchange method. Chemosphere 2004, 56, 91-106. [CrossRef] [PubMed]

36. Charerntanyarak, L. Heavy metals removal by chemical coagulation and precipitation. Water Sci. Technol. 1999, 39, 135-138. [CrossRef]

37. Kumar, B.; Smita, K.; Flores, L.C. Plant mediated detoxification of mercury and lead. Arabian J. Chem. 2017, 10, S2335-S2342. [CrossRef]

38. Kumari, P. A low cost material, banana peel for the removal of lead (II) from aqueous solutions. Int. Res. J. Eng. Technol. 2017, 4, 1404-1406.

39. Liu, P.; Yan, T.; Zhang, J.; Shi, L.; Zhang, D. Separation and recovery of heavy metal ions and salt ions from wastewater by 3D graphene-based asymmetric electrodes via capacitive deionization. J. Mater. Chem. A 2017, 5, 14748-14757. [CrossRef]

40. Guo, R.; Wang, R.; Yin, J.; Jiao, T.; Huang, H.; Zhao, X.; Zhang, L.; Li, Q.; Zhou, J.; Peng, Q. Fabrication and highly efficient dye removal characterization of beta-cyclodextrin-based composite polymer fibers by electrospinning. Nanomaterials 2019, 9, 127. [CrossRef]

41. Yusuf, M.; Elfghi, F.M.; Zaidi, S.A.; Abdullaha, E.C.; Khan, M.A. Applications of graphene and its derivatives as an adsorbent for heavy metal and dye removal: a systematic and comprehensive overview. RSC Adv. 2015, 5, 50392-50420. [CrossRef]

42. Fan, Q.; Li, Z.; Zhao, H.; Jia, Z.; Xu, J.; Wu, W. Adsorption of $\mathrm{Pb}(\mathrm{II})$ on palygorskite from aqueous solution: Effects of pH, ionic strength and temperature. Appl. Clay Sci. 2009, 45, 111-116. [CrossRef]

43. Zhang, F.; Wang, B.; He, S.; Man, R. Preparation of graphene-oxide/polyamidoamine dendrimers and their adsorption properties toward some heavy metal ions. J. Chem. Eng. Data 2014, 59, 1719-1726. [CrossRef] 
44. Yu, R.; Shi, Y.; Yang, D.; Liu, Y.; Qu, J.; Yu, Z.-Z. Graphene oxide/chitosan aerogel microspheres with honeycomb-Cobweb and radially oriented microchannel structures for broad spectrum and rapid adsorption of water contaminants. ACS Appl. Mater. Interfaces 2017, 9, 21809-21819. [CrossRef] [PubMed]

45. Ali, I.; Gupta, V.K. Advances in water treatment by adsorption technology. Nat. Protoc. 2006, 1, $2661-2667$. [CrossRef] [PubMed]

46. Dabrowski, A. Adsorption-from theory to practice. Adv. Colloid Interface Sci. 2001, 93, 135-224. [CrossRef]

47. Shen, Y.; Chen, B. Sulfonated graphene nanosheets as a superb adsorbent for various environmental pollutants in water. Environ. Sci. Technol. 2015, 49, 7364-7372. [CrossRef] [PubMed]

48. La, D.D.; Thi, H.P.N.; Nguyen, T.A.; Bhosale, S.V. Effective removal of Pb(II) using a graphene@ternary oxides composite as an adsorbent in aqueous media. New J. Chem. 2017, 41, 14627-14634. [CrossRef]

49. Khajeh, M.; Laurent, S.; Dastafkan, K. Nanoadsorbents: classification, preparation, and applications (with emphasis on aqueous media). Chem. Rev. 2013, 113, 7728-7768. [CrossRef] [PubMed]

50. Yang, S.; Hu, J.; Chen, C.; Shao, D.; Wang, X. Mutual effects of Pb(II) and humic acid adsorption on multiwalled carbon nanotubes/polyacrylamide composites from aqueous solutions. Environ. Sci. Technol. 2011, 45, 3621-3627. [CrossRef]

51. Bulbula, S.T.; Dong, Y.; Lu, Y.; Yang, X.-Y. Graphene oxide coating enhances adsorption of lead ions on mesoporous $\mathrm{SiO}_{2}$ spheres. Chem. Lett. 2018, 47, 210-212. [CrossRef]

52. Ali, I. New generation adsorbents for water treatment. Chem. Rev. 2012, 112, 5073-5091. [CrossRef] [PubMed]

53. Zou, Y.; Wang, X.; Khan, A.; Wang, P.; Liu, Y.; Alsaedi, A.; Hayat, T.; Wang, X. Environmental remediation and application of nanoscale zero-valent iron and its composites for the removal of heavy metal ions: A review. Environ. Sci. Technol. 2016, 50, 7290-7304. [CrossRef] [PubMed]

54. Yu, S.; Wang, X.; Pang, H.; Zhang, R.; Song, W.; Fu, D.; Hayat, T.; Wang, X. Boron nitride-based materials for the removal of pollutants from aqueous solutions: A review. Chem. Eng. J. 2018, 333, 343-360. [CrossRef]

55. Sharma, V.K.; McDonald, T.J.; Jim, H.; Garg, V.K. Magnetic graphene-carbon nanotube iron nanocomposites as adsorbents and antibacterial agents for water purification. Adv. Colloid Interface Sci. 2015, 225, 229-240. [CrossRef] [PubMed]

56. Kyzas, G.Z.; Matis, K.A. Nanoadsorbents for pollutants removal: A review. J. Mol. Liq. 2015, 203, $159-168$. [CrossRef]

57. Bhatia, M.; Babu, R.S.; Sonawane, S.H.; Gogate, P.R.; Girdhar, A.; Reddy, E.R.; Pola, M. Application of nanoadsorbents for removal of lead from water. Int. J. Environ. Sci. Technol. 2017, 14, 1135-1154. [CrossRef]

58. Zhao, L.; Deng, J.; Sun, P.; Liu, J.; Yang, Y. Nanomaterials for treating emerging contaminants in water by adsorption and photocatalysis: Systematic review and bibliometric analysis. Sci. Total Environ. 2018, 627, 1253-1263. [CrossRef]

59. Sophia, C.A.; Lima, E.C. Removal of emerging contaminants from the environment by adsorption. Ecotoxicol. Environ. Saf. 2018, 150, 1-17. [CrossRef]

60. Nupearachchi, C.N.; Mahatantila, K.; Vithanage, M. Application of graphene for decontamination of water; Implications for sorptive removal. Groundwater Sustain. Dev. 2017, 5, 206-215. [CrossRef]

61. Adeleye, A.S.; Conway, J.R.; Garner, K.; Huang, Y.; Su, Y.; Keller, A.A. Engineered nanomaterials for water treatment and remediation: Costs, benefits, and applicability. Chem. Eng. J. 2016, 286, 640-662. [CrossRef]

62. Bora, T.; Dutta, J. Applications of nanotechnology in wastewater treatment-A review. J. Nanosci. Nanotechnol. 2014, 14, 613-626. [CrossRef] [PubMed]

63. Qu, X.; Alvarez, P.J.J.; Li, Q. Applications of nanotechnology in water and wastewater treatment. Water Res. 2013, 47, 3931-3946. [CrossRef] [PubMed]

64. Cai, Z.; Dwivedi, A.D.; Lee, W.-N.; Zhao, X.; Liu, W.; Sillanpõõ, M.; Zhao, D.; Huang, C.-H.; Fu, J. Application of nanotechnologies for removing pharmaceutically active compounds from water: development and future trends. Environ. Sci. Nano 2018, 5, 27-47. [CrossRef]

65. Jiang, M.; Qi, Y.; Liu, H.; Chen, Y. The role of nanomaterials and nanotechnologies in wastewater treatment: a bibliometric analysis. Nanoscale Res. Lett. 2018, 13, 233. [CrossRef] [PubMed]

66. Das, R.; Vecitis, C.D.; Schulze, A.; Cao, B.; Ismail, A.F.; Lu, X.; Chen, J.; Ramakrishna, S. Recent advances in nanomaterials for water protection and monitoring. Chem. Soc. Rev. 2017, 46, 6946-7020. [CrossRef] [PubMed]

67. Zhao, G.; Li, J.; Ren, X.; Chen, C.; Wang, X. Few-layered graphene oxide nanosheets as superior sorbents for heavy metal ion pollution management. Environ. Sci. Technol. 2011, 45, 10454-10462. [CrossRef] [PubMed] 
68. Zhang, Y.; Wu, B.; Xu, H.; Liu, H.; Wang, M.; He, Y.; Pan, B. Nanomaterials-enabled water and wastewater treatment. NanoImpact 2016, 3-4, 22-39. [CrossRef]

69. Santhosh, C.; Velmurugan, V.; Jacob, G.; Jeong, S.K.; Grace, A.N.; Bhatnagar, A. Role of nanomaterials in water treatment applications: A review. Chem. Eng. J. 2016, 306, 1116-1137. [CrossRef]

70. Hu, L.; Li, Y.; Zhang, X.; Wang, Y.; Cui, L.; Wei, Q.; Ma, H.; Yan, L.; Du, B. Fabrication of magnetic watersoluble hyperbranched polyol functionalized graphene oxide for high-efficiency water remediation. Sci. Rep. 2016, 6, 28924. [CrossRef] [PubMed]

71. Burakov, A.E.; Galunin, E.V.; Burakova, I.V.; Kucherova, A.E.; Agarwal, S.; Tkachev, A.G.; Gupta, V.K. Adsorption of heavy metals on conventional and nanostructured materials for wastewater treatment purposes: A review. Ecotoxicol. Environ. Saf. 2018, 148, 702-712. [CrossRef]

72. Yang, J.; Wu, J.-X.; Lü, Q.-F.; Lin, T.-T. Facile preparation of lignosulfonate-graphene oxide-polyaniline ternary nanocomposite as an effective adsorbent for $\mathrm{Pb}(\mathrm{II})$ ions. ACS Sustain. Chem. Eng. 2014, 2, 1203-1211. [CrossRef]

73. Zhao, T.; Yao, Y.; Wang, M.; Chen, R.; Yu, Y.; Wu, F.; Zhang, C. Preparation of $\mathrm{MnO}_{2}$-modified graphite sorbents from spent Li-ion batteries for the treatment of water contaminated by lead, cadmium, and silver. ACS Appl. Mater. Interfaces 2017, 9, 25369-25376. [CrossRef] [PubMed]

74. Shilimkar, T.N.; Anuse, M.A. Rapid extraction oflead(II) from succinate media with n-octylaniline in toluene. Sep. Purif. Technol. 2002, 26, 185-193. [CrossRef]

75. Wojciechowska, A.; Wieszczycka, K.; Wojciechowska, I.; Olszanowski, A. Lead (II) extraction from aqueous solutions by pyridine extractants. Sep. Purif. Technol. 2017, 177, 239-248. [CrossRef]

76. Chanthapon, N.; Sarkar, S.; Kidkhunthod, P.; Padungthon, S. Lead removal by a reusable gel cation exchange resin containing nano-scale zero valent iron. Chem. Eng. J. 2018, 331, 545-555. [CrossRef]

77. Rahman, N.; Haseen, U.; Rashid, M. Synthesis and characterization of polyacrylamide zirconium (IV) iodate ion-exchanger: its application for selective removal of lead (II) from wastewater. Arabian J. Chem. 2017, 10, S1765-S1773. [CrossRef]

78. Pehlivan, E.; Altun, T. Ion-exchange of $\mathrm{Pb}^{2+}, \mathrm{Cu}^{2+}, \mathrm{Zn}^{2+}, \mathrm{Cd}^{2+}$, and $\mathrm{Ni}^{2+}$ ions from aqueous solution by Lewatit CNP 80. J. Hazard. Mater. 2007, 140, 299-307. [CrossRef]

79. Ghaemi, N.; Zereshki, S.; Heidari, S. Removal of lead ions from water using PES-based nanocomposite membrane incorporated with polyaniline modified GO nanoparticles: Performance optimization by central composite design. Process Saf. Environ. Prot. 2017, 111, 475-490. [CrossRef]

80. Hajdu, I.; Bodnár, M.; Csikós, Z.; Wei, S.; Daróczi, L.; Kovács, B.; Győri, Z.; Tamás, J.; Borbély, J. Combined nano-membrane technology for removal of lead ions. J. Membr. Sci. 2012, 409-410, 44-53. [CrossRef]

81. Mehdipour, S.; Vatanpour, V.; Kariminia, H.-R. Influence of ion interaction on lead removal by a polyamide nanofiltration membrane. Desalination 2015, 362, 84-92. [CrossRef]

82. Sun, J.; Wu, L.; Li, Y. Removal of lead ions from polyether sulfone/ $\mathrm{Pb}(\mathrm{II})$-imprinted multi-walled carbon nanotubes mixed matrix membrane. J. Taiwan Inst. Chem. Eng. 2017, 78, 219-229. [CrossRef]

83. Gholami, A.; Moghadassi, A.R.; Hosseinia, S.M.; Shabani, S.; Gholami, F. Preparation and characterization of polyvinyl chloride based nanocomposite nanofiltration-membrane modified by iron oxide nanoparticles for lead removal from water. J. Ind. Eng. Chem. 2014, 20, 1517-1522. [CrossRef]

84. Xu, C.; Cui, A.; Xu, Y.; Fu, X. Graphene oxide- $\mathrm{TiO}_{2}$ composite filtration membranes and their potential application for water purification. Carbon 2013, 62, 465-471. [CrossRef]

85. Mattia, D.; Lee, K.P.; Calabrò, F. Water permeation in carbon nanotube membranes. Curr. Opin. Chem. Eng. 2014, 4, 32-37. [CrossRef]

86. Calabrò, F. Modeling the effects of material chemistry on water flow enhancement in nanotube membranes. MRS Bull. 2017, 42, 289-293.

87. Zhaoa, D.; Zhaoa, J.; Ji, Y.; Liu, G.; Liu, S.; Jin, W. Facilitated water-selective permeation via PEGylation of graphene oxide membrane. J. Membr. Sci. 2018, 567, 311-320. [CrossRef]

88. Matlock, M.M.; Howerton, B.S.; Atwood, D.A. Chemical precipitation of heavy metals from acid mine drainage. Water Res. 2002, 36, 4757-4764. [CrossRef]

89. Huisman, J.L.; Schouten, G.; Schultz, C. Biologically produced sulphide for purification of process streams, effluent treatm ent and recovery of metals in the metal and mining industry. Hydrometallurgy 2006, 83, 106-113. [CrossRef] 
90. Wang, T.; Jin, X.; Chen, Z.; Megharaj, M.; Naidu, R. Simultaneous removal of Pb(II) and Cr(III) by magnetite nanoparticles using various synthesis conditions. J. Ind. Eng. Chem. 2014, 20, 3543-3549. [CrossRef]

91. Prihasto, N.; Liu, Q.F.; Kim, S.-H. Pre-treatment strategies for seawater desalination by reverse osmosis system. Desalination 2009, 249, 308-316. [CrossRef]

92. Vidales, M.J.M.d.; Millán, M.; Sáez, C.; Cañizares, P.; Rodrigo, M.A. Irradiated-assisted electrochemical processes for the removal of persistent pollutants from real wastewater. Sep. Purif. Technol. 2017, 175, 428-434. [CrossRef]

93. Liu, Y.; Yan, J.; Yuan, D.; Li, Q.; Wu, X. The study of lead removal from aqueous solution using an electrochemical method with a stainless steel net electrode coated with single wall carbon nanotubes. Chem. Eng. J. 2013, 218, 81-88. [CrossRef]

94. Hussin, F.; Abnisa, F.; Issabayeva, G.; Aroua, M.K. Removal of lead by solar-photovoltaic electrocoagulation using novel perforated zinc electrode. J. Clean. Prod. 2017, 147, 206-216. [CrossRef]

95. Pang, F.M.; Kumar, P.; Teng, T.T.; Omar, A.K.M.; Wasewar, K.L. Removal of lead, zinc and iron by coagulation-flocculation. J. Taiwan Inst. Chem. Eng. 2011, 42, 809-815. [CrossRef]

96. Sweetman, M.J.; May, S.; Mebberson, N.; Pendleton, P.; Vasilev, K.; Plush, S.E.; Hayball, J.D. Activated carbon, carbon nanotubes and graphene: materials and composites for advanced water purification. C J. Carbon Res. 2017, 3, 18. [CrossRef]

97. Zhao, J.; Wang, Z.; White, J.C.; Xing, B. Graphene in the aquatic environment: Adsorption, dispersion, toxicity and transformation. Environ. Sci. Technol. 2014, 48, 9995-10009. [CrossRef] [PubMed]

98. Ren, X.; Chen, C.; Nagatsu, M.; Wang, X. Carbon nanotubes as adsorbents in environmental pollution management: A review. Chem. Eng. J. 2011, 170, 395-410. [CrossRef]

99. Tehrani, M.S.; Azar, P.A.; Namin, P.E.; Dehaghi, S.M. Removal of lead ions from wastewater using functionalized multiwalled carbon nanotubes with tris(2-aminoethyl)amine. J. Environ. Protect. 2013, 4, 529-536. [CrossRef]

100. Taylor, R.M.; Kuennen, R.W. Removing lead in drinking water with activated carbon. Environ. Prog. 1994, 13, 65-71. [CrossRef]

101. Goel, J.; Kadirvelu, K.; Rajagopal, C.; Garg, V.K. Removal of lead(II) by adsorption using treated granular activated carbon: Batch and column studies. J. Hazard. Mater. 2005, 125, 211-220. [CrossRef]

102. Zaini, M.A.; Amano, Y.; Machida, M. Adsorption of heavy metals onto activated carbons derived from polyacrylonitrile fiber. J. Hazard. Mater. 2010, 180, 552-560. [CrossRef] [PubMed]

103. Machida, M.; Fotoohi, B.; Amamo, Y.; Ohba, T.; Kanoh, H.; Mercier, L. Cadmium(II) adsorption using functional mesoporous silica and activated carbon. J. Hazard. Mater. 2012, 221-222, 220-227. [CrossRef] [PubMed]

104. Machida, M.; Fotoohi, B.; Amamo, Y.; Mercier, L. Cadmium(II) and lead(II) adsorption onto hetero-atom functional mesoporous silica and activated carbon. Appl. Surf. Sci. 2012, 258, 7389-7394. [CrossRef]

105. Mohan, D.; Singh, K.P.; Singh, V.K. Wastewater treatment using low cost activated carbons derived from agricultural byproducts-A case study. J. Hazard. Mater. 2008, 152, 1045-1053. [CrossRef] [PubMed]

106. Wang, J.; Chen, Z.; Chen, B. Adsorption of polycyclic aromatic hydrocarbons by graphene and graphene oxide nanosheets. Environ. Sci. Technol. 2014, 48, 4817-4825. [CrossRef]

107. Shen, Y.; Fang, Q.; Chen, B. Environmental applications of three-dimensional graphene-based macrostructures: Adsorption, transformation, and detection. Environ. Sci. Technol. 2015, 49, 67-84. [CrossRef]

108. Seenivasan, R.; Chang, W.-J.; Gunasekaran, S. Highly sensitive detection and removal of lead ions in water using cysteine-functionalized graphene oxide/polypyrrole nanocomposite film electrode. ACS Appl. Mater. Interfaces 2015, 7, 15935-15943. [CrossRef]

109. Falahati, F.; Baghdadi, M.; Aminzadeh, B. Treatment of dairy wastewater by graphene oxide nanoadsorbent and sludge separation, using in situ sludge magnetic impregnation (ISSMI). Pollution 2018, 4, $29-41$.

110. Kyzas, G.Z.; Deliyanni, E.A.; Bikiaris, D.N.; Mitropoulos, A.C. Graphene composites as dye adsorbents: Review. Chem. Eng. Res. Des. 2018, 129, 75-88. [CrossRef]

111. Lua, N.; He, G.; Liua, J.; Liu, G.; Li, J. Combustion synthesis of graphene for water treatment. Ceram. Intern. 2018, 44, 2463-2469. [CrossRef]

112. Zhang, Y.; Yan, X.; Yan, Y.; Chen, D.; Huang, L.; Zhang, J.; Ke, Y.; Tan, S. The utilization of a three-dimensional reduced graphene oxide and montmorillonite composite aerogel as a multifunctional agent for wastewater treatment. RSC Adv. 2018, 8, 4239-4248. [CrossRef] 
113. Moharram, M.A.K.; Tohami, K.; Hotaby, W.M.E.; Bakr, A.M. Graphene oxide porous crosslinked cellulose nanocomposite microspheres for lead removal: Kinetic study. React. Funct. Polym. 2016, 101,9-19. [CrossRef]

114. Tabish, T.A.; Memon, F.A.; Gomez, D.E.; Horsell, D.W.; Zhang, S. A facile synthesis of porous graphene for efcient water and wastewater treatment. Sci. Rep. 2018, 8, 1817. [CrossRef] [PubMed]

115. You, Y.; Jin, X.H.; Wen, X.Y.; Sahajwalla, V.; Chen, V.; Bustamante, H.; Joshi, R.K. Application of graphene oxide membranes for removal of natural organic matter from water. Carbon 2018, 129, 415-419. [CrossRef]

116. Suárez-Iglesias, O.; Collado, S.; Oulego, P.; Díaz, M. Graphene-family nanomaterials in wastewater treatment plants. Chem. Eng. J. 2017, 313, 121-135. [CrossRef]

117. Wang, S.; Sun, H.; Ang, H.M.; Tadé, M.O. Adsorptive remediation of environmental pollutants using novel graphenebased nanomaterials. Chem. Eng. J. 2013, 226, 336-347. [CrossRef]

118. Deng, J.-H.; Zhang, X.-R.; N, G.-M.Z.; N, J.-L.G.; Niu, Q.-Y.; Liang, J. Simultaneous removal of Cd(II) and ionic dyes from aqueous solution using magnetic graphene oxide nanocomposite as an adsorbent. Chem. Eng. J. 2013, 226, 189-200. [CrossRef]

119. Wu, Z.g.; Deng, W.; Zhou, W.; Luo, J. Novel magnetic polysaccharide/graphene oxide @ $\mathrm{Fe}_{3} \mathrm{O}_{4}$ gel beads for adsorbing heavy metal ions. Carbohyd. Polym. 2019, 216, 119-128. [CrossRef]

120. Usman, T.M.; Xintai, S.; Mengqi, Z.; Yinnian, L.; Ronglan, W.; Dejun, C. Preparation of hydroxypropyl-cyclodextrin-graphene $/ \mathrm{Fe}_{3} \mathrm{O}_{4}$ and its adsorption properties for heavy metals. Surf. Interfac. 2019, 16, 43-49.

121. Huang, D.; Wu, J.; Wang, L.; Liu, X.; Meng, J.; Tang, X.; Tang, C.; Xu, J. Novel insight into adsorption and co-adsorption of heavy metal ions and an organic pollutant by magnetic graphene nanomaterials in water. Chem. Eng. J. 2019, 358, 1399-1409. [CrossRef]

122. Mehta, D.; Mazumdar, S.; Singh, S.K. Magnetic adsorbents for the treatment of water/wastewater-A review. J. Water Process Eng. 2015, 7, 244-265. [CrossRef]

123. Wang, Y.; Li, L.; Luo, C.; Wang, X.; Duan, H. Removal of $\mathrm{Pb}^{2+}$ from water environment using a novel magnetic chitosan/graphene oxide imprinted $\mathrm{Pb}^{2+}$. Int. J. Biolog. Macromol. 2016, 86, 505-511. [CrossRef] [PubMed]

124. Mahmud, H.N.M.E.; Huq, A.K.O.; Yahyaa, R.b. The removal of heavy metal ions from wastewater/aqueous solution using polypyrrole-based adsorbents: a review. RSC Adv. 2016, 6, 14778-14791. [CrossRef]

125. Alawa, B.; Srivstava, J.K.; Srivastava, A.; Palsania, J. Adsorption of heavy metal Pb(II) from synthetic waste water by polypyrrole composites. Int. J. Chem. Stud. 2015, 3, 4-8.

126. Mahmud, H.N.M.E.; Huq, A.K.O.; Yahya, R. Polymer-based adsorbent for heavy metals removal from aqueous solution. Mater. Sci. Eng. 2017, 206, 012100. [CrossRef]

127. Alaba, P.A.; Oladoja, N.A.; Sani, Y.M.; Ayodele, O.B.; Mohammed, I.Y.; Olupinla, S.F.; Daud, W.M.W. Insight into wastewater decontamination using polymeric adsorbents. J. Environ. Chem. Eng. 2018, 6, 1651-1672. [CrossRef]

128. El-Kafrawy, A.F.; El-Saeed, S.M.; Farag, R.K.; El-Saied, H.A.-A.; El-SayedAbdel-Raouf, M. Adsorbents based on natural polymers for removal of some heavy metals from aqueous solution. Egypt. J. Pet. 2017, 26, $23-32$. [CrossRef]

129. Malik, H.; Qureshi, U.A.; Muqeet, M.; Mahar, R.B.; Ahmed, F.; Khatri, Z. Removal of lead from aqueous solution using polyacrylonitrile/magnetite nanofibers. Environ. Sci. Pollut. Res. 2018, 25, 3557-3564. [CrossRef]

130. Hamouz, O.C.S.A.; Akintola, O.S. Removal of lead and arsenic ions by a new series of aniline based polyamines. Process Saf. Environ. Prot. 2017, 106, 180-190. [CrossRef]

131. Zare, E.N.; Motahari, A.; Sillanpää, M. Nanoadsorbents based on conducting polymer nanocomposites with main focus on polyaniline and its derivatives for removal of heavy metal ions/dyes: A review. Environ. Res. 2018, 162, 173-195. [CrossRef]

132. Sajid, M.; Nazal, M.K.; Baig, N.; Osman, A.M. Removal of heavy metals and organic pollutants from water using dendritic polymers based adsorbents: A critical review. Sep. Purif. Technol. 2018, 191, 400-423. [CrossRef]

133. Hu, R.; Wang, X.; Dai, S.; Shao, D.; Hayat, T.; Alsaedi, A. Application of graphitic carbon nitride for the removal of $\mathrm{Pb}$ (II) and aniline from aqueous solutions. Chem. Eng. J. 2015, 260, 469-477. [CrossRef]

134. Ding, C.; Cheng, W.; Wang, X.; Wu, Z.-Y.; Sun, Y.; Chen, C.; Wang, X.; Yu, S.-H. Competitive sorption of Pb(II), $\mathrm{Cu}(\mathrm{II})$ and $\mathrm{Ni}(\mathrm{II})$ on carbonaceous nanofibers: A spectroscopic and modeling approach. J. Hazard. Mater. 2016, 313, 253-261. [CrossRef] [PubMed] 
135. Huang, S.; Song, S.; Zhang, R.; Wen, T.; Wang, X.; Yu, S.; Song, W.; Hayat, T.; Alsaedi, A.; Wang, X. Construction of layered double hydroxides/hollow carbon microsphere composites and Its applications for mutual removal of $\mathrm{Pb}(\mathrm{II})$ and humic acid from aqueous solutions. ACS Sustain. Chem. Eng. 2017, 5, 11268-11279. [CrossRef]

136. Du, Y.; Wang, J.; Zou, Y.; Yao, W.; Hou, J.; Xia, L.; Peng, A.; Alsaedi, A.; Hayat, T.; Wang, X. Synthesis of molybdenum disulfide/reduced graphene oxide composites for effective removal of $\mathrm{Pb}$ (II) from aqueous solutions. Sci. Bull. 2017, 62, 913-922. [CrossRef]

137. Hua, M.; Zhang, S.; Pan, B.; Zhang, W.; Lv, L.; Zhang, Q. Heavy metal removal from water/wastewater by nanosized metal oxides: A review. J. Hazard. Mater. 2012, 211-212, 317-331. [CrossRef] [PubMed]

138. Abbasa, A.; Al-Amera, A.M.; Laoui, T.; Al-Marri, M.J.; Nasser, M.S.; Khraisheh, M.; Atieh, M.A. Heavy metal removal from aqueous solution by advanced carbon nanotubes: Critical review of adsorption. Sep. Purif. Technol. 2016, 157, 141-161.

139. Tehrani, M.S.; Azar, P.A.; namin, P.E.; Dehaghi, S.M. Removal of lead ions from aqueous solution using multi-walled carbon nanotubes: The effect of functionalization. J. Appl. Environ. Biol. Sci. 2014, 4, 316-326.

140. Xu, J.; Cao, Z.; Zhang, Y.; Yuan, Z.; Lou, Z.; Xu, X.; Wang, X. A review of functionalized carbon nanotubes and graphene for heavy metal adsorption from water: Preparation, application, and mechanism. Chemosphere 2018, 195, 351-364. [CrossRef]

141. Farghali, A.A.; Tawab, H.A.A.; Moaty, S.A.A.; Khaled, R. Functionalization of acidified multi-walled carbon nanotubes for removal of heavy metals in aqueous solutions. J. Nanostr. Chem. 2017, 7, 101-111. [CrossRef]

142. Anitha, K.; Namsani, S.; Singh, J.K. Removal of heavy metal ions using a functionalized single-walled carbon nanotube: A molecular dynamics study. J. Phys. Chem. A 2015, 119, 8349-8358. [CrossRef] [PubMed]

143. Melo, B.A.G.d.; Motta, F.L.; Santana, M.H.A. Humic acids: Structural properties and multiple functionalities for novel technological developments. Mater. Sci. Eng. C 2016, 62, 967-974. [CrossRef] [PubMed]

144. Kyzas, G.Z.; Deliyanni, E.A.; Matis, K.A. Graphene oxide and its application as an adsorbent for wastewater treatment. J. Chem. Technol. Biotechnol. 2014, 89, 196-205. [CrossRef]

145. Li, X.; Wang, X.; Zhang, L.; Lee, S.; Dai, H. Chemically derived, ultrasmooth graphene nanoribbon semiconductors. Science 2008, 319, 1229-1232. [CrossRef] [PubMed]

146. Kumar, M.; Singh, K.; Dhawan, S.K.; Tharanikkarasu, K.; Chung, J.S.; Kong, B.-S.; Kim, E.J.; Hur, S.H. Synthesis and characterization of covalently-grafted graphene polyaniline nanocomposites and its use in a supercapacitor. Chem. Eng. J. 2013, 231, 397-405. [CrossRef]

147. Cai, W.W.; Piner, R.D.; Stadermann, F.J.; Park, S.; Shaibat, M.A.; Ishii, Y.; Yang, D.X.; Velamakanni, A.; An, S.J.; Stoller, M.; et al. Synthesis and solid-state NMR structural characterization of 13C-labeled graphite oxide. Science 2008, 321, 1815-1817. [CrossRef] [PubMed]

148. Geim, A.K. Graphene: Status and Prospects. Science 2009, 324, 1530-1534. [CrossRef]

149. Sahu, A.; Choi, W.I.; Tae, G. A stimuli-sensitive injectable graphene oxide composite hydrogel. Chem. Commun. 2012, 48, 5820-5822. [CrossRef]

150. Bao, J.; Fu, Y.; Bao, Z. Thiol-functionalized magnetite/graphene oxide hybrid as a reusable adsorbent for $\mathrm{Hg}^{2+}$ removal. Nanoscale Res. Lett. 2013, 8, 486. [CrossRef]

151. Repo, E.; Warchoł, J.K.; Bhatnagar, A.; Mudhoo, A.; Sillanpää, M. Aminopolycarboxylic acid functionalized adsorbents for heavy metals removal from water. Water Res. 2013, 47, 4812-4832. [CrossRef]

152. Nair, R.R.; Wu, H.A.; Jayaram, P.N.; Grigorieva, I.V.; Geim, A.K. Unimpeded permeation of water through helium-leak-tight graphene-based membranes. Science 2012, 335, 442-444. [CrossRef] [PubMed]

153. Peng, W.; Li, H.; Liu, Y.; Song, S. A review on heavy metal ions adsorption from water by graphene oxide and its composites. J. Mol. Liq. 2017, 230, 496-504. [CrossRef]

154. Gao, Y.; Pan, L.; Li, H.; Zhang, Y.; Zhang, Z.; Chen, Y.; Sun, Z. Electrosorption behavior of cations with carbon nanotubes and carbon nanofibres composite film electrodes. Thin Solid Films 2009, 517, 1616-1619. [CrossRef]

155. Goel, J.; Kadirvelu, K.; Rajagopal, C.; Garg, V.K. Removal of lead(II) from aqueous solution by adsorption on carbon aerogel Using a response surface methodological approach. Ind. Eng. Chem. Res. 2005, 44, 1987-1994. [CrossRef]

156. Bain, E.J.; Calo, J.M.; Spitz-Steinberg, R.; Kirchner, J.; Axén, J. Electrosorption/electrodesorption of arsenic on a granular activated carbon in the presence of other heavy metals. Energy Fuels 2010, 24, 3415-3421. [CrossRef] [PubMed] 
157. Gabelich, C.J.; Tran, T.D.; Suffet, I.H.M. Electrosorption of inorganic salts from aqueous solution using carbon aerogels. Environ. Sci. Technol. 2002, 36, 3010-3019. [CrossRef]

158. Kuchta, B.; Firlej, L.; Maurin, G. Modeling of adsorption in nanopores. J. Mol. Model. 2005, 11, $293-300$. [CrossRef]

159. Hyung, H.; Fortner, J.D.; Hughes, J.B.; Kim, J.-H. Natural organic matter stabilizes carbon nanotubes in the aqueous phase. Environ. Sci. Technol. 2007, 41, 179-184. [CrossRef]

160. Stafiej, A.; Pyrzynska, K. Adsorption of heavy metal ions with carbon nanotubes. Sep. Purif. Technol. 2007, 58, 49-52. [CrossRef]

161. Wang, H.; Zhou, A.; Peng, F.; Yu, H.; Yang, J. Mechanism study on adsorption of acidified multiwalled carbon nanotubes to $\mathrm{Pb}(\mathrm{II})$. J. Colloid Interface Sci. 2007, 316, 277-283. [CrossRef]

162. Schierz, A.; Zänker, H. Aqueous suspensions of carbon nanotubes: surface oxidation, colloidal stability and uranium sorption. Environ. Pollut. 2009, 157, 1088-1094. [CrossRef] [PubMed]

163. Huang, Z.-H.; Zheng, X.; Lv, W.; Wang, M.; Yang, Q.-H.; Kang, F. Adsorption of lead(II) ions from aqueous solution on low-temperature exfoliated graphene nanosheets. Langmuir 2011, 27, 7558-7562. [CrossRef] [PubMed]

164. Madadrang, C.J.; Kim, H.Y.; Gao, G.; Wang, N.; Zhu, J.; Feng, H.; Gorring, M.; Kasner, M.L.; Hou, S. Adsorption behavior of EDTA-graphene oxide for $\mathrm{Pb}(\mathrm{II})$ removal. ACS Appl. Mater. Interfaces 2012, 4, 1186-1193. [CrossRef] [PubMed]

165. Oyetade, O.A.; Nyamori, V.O.; Martincigh, B.S.; Jonnalagadda, S.B. Effectiveness of carbon nanotube-cobalt ferrite nanocomposites for the adsorption of rhodamine B from aqueous solutions. RSC Adv. 2015, 5, 22724-22739. [CrossRef]

166. Oyetade, O.A.; Nyamori, V.O.; Martincigh, B.S.; Jonnalagadda, S.B. Nitrogen-functionalised carbon nanotubes as a novel adsorbent for the removal of $\mathrm{Cu}$ (II) from aqueous solution. RSC Adv. 2016, 6, 2731-2745. [CrossRef]

167. Wang, H.J.; Zhou, A.L.; Peng, F.; Yu, H.; Chen, L.F. Adsorption characteristic of acidified carbon nanotubes for heavy metal $\mathrm{Pb}$ (II) in aqueous solution. Mater. Sci. Eng. A 2007, 466, 201-206. [CrossRef]

168. Norzilah, A.H.; Fakhru'l-Razi, A.; Choong, T.S.Y.; Chuah, A.L. Surface modification effects on CNTs adsorption of methylene blue and phenol. J. Nanomater. 2011, 2011,1-18. [CrossRef]

169. Lu, C.; Chiu, H. Chemical modification of multiwalled carbon nanotubes for sorption of $\mathrm{Zn}^{2+}$ from aqueous solution. Chem. Eng. J. 2008, 139, 462-468. [CrossRef]

170. Li, Y.-H.; Wang, S.; Luan, Z.; Ding, J.; Xu, C.; Wu, D. Adsorption of cadmium(II) from aqueous solution by surface oxidized carbon nanotubes. Carbon 2003, 41, 1057-1062. [CrossRef]

171. Xu, D.; Tan, X.; Chen, C.; Wang, X. Removal of $\mathrm{Pb}(\mathrm{II})$ from aqueous solution by oxidized multiwalled carbon nanotubes. J. Hazard. Mater. 2008, 154, 407-416. [CrossRef]

172. Machida, M.; Mochimaru, T.; Tatsumoto, H. Lead(II) adsorption onto the graphene layer of carbonaceous materials in aqueous solution. Carbon 2006, 44, 2681-2688. [CrossRef]

173. Hamza, I.A.A.; Martincigh, B.S.; Ngila, J.C.; Nyamoria, V.O. Adsorption studies of aqueous Pb(II) onto a sugarcane bagasse/ multi-walled carbon nanotube composite. Phys. Chem. Earth 2013, 66, 157-166. [CrossRef]

174. Varadwaj, G.B.B.; Oyetade, O.A.; Rana, S.; Martincigh, B.S.; Jonnalagadda, S.B.; Nyamori, V.O. Facile synthesis of three-dimensional $\mathrm{Mg}-\mathrm{Al}$ layered double hydroxide/partially reduced graphene oxide nanocomposites for the effective removal of $\mathrm{Pb}^{2+}$ from aqueous solution. ACS Appl. Mater. Interfaces 2017, 9, 17290-17305. [CrossRef] [PubMed]

175. Wan, W.; Zhao, Z.; Hughes, T.C.; Qian, B.; Peng, S.; Hao, X.; Qiu, J. Graphene oxide liquid crystal pickering emulsions and their assemblies. Carbon 2015, 85, 16-23. [CrossRef]

176. Khan, T.A.; Dahiya, S.; Ali, I. Use of kaolinite as adsorbent: Equilibrium, dynamics and thermodynamic studies on the adsorption of rhodamine B from aqueous solution. Appl. Clay Sci. 2012, 69, 58-66. [CrossRef]

177. Srivastava, R.; Rupainwar, D. Eucalyptus bark powder as an effective adsorbent: Evaluation of adsorptive characteristics for various dyes. Desalin. Water Treat. 2009, 11, 302-313. [CrossRef]

178. Sitko, R.; Turek, E.; Zawisza, B.; Malicka, E.; Talik, E.; Heimann, J.; Gagor, A.; Feist, B.; Wrzalik, R. Adsorption of divalent metal ions from aqueous solutions using graphene oxide. Dalton Trans. 2013, 42, 5682-5689. [CrossRef] [PubMed]

179. Liu, Y.; Liu, Y.-J. Biosorption isotherms, kinetics and thermodynamics. Sep. Purif. Technol. 2008, 61, $229-242$. [CrossRef] 
180. Wei, Y.; Xu, L.; Tao, Y.; Yao, C.; Xue, H.; Kong, Y. Electrosorption of lead ions by nitrogen-doped graphene aerogels via one-pot hydrothermal route. Ind. Eng. Chem. Res. 2016, 55, 1912-1920. [CrossRef]

181. He, S.; Zhang, F.; Cheng, S.; Wang, W. Synthesis of sodium acrylate and acrylamide copolymer/GO hydrogels and their effective adsorption for $\mathrm{Pb}^{2+}$ and $\mathrm{Cd}^{2+}$. ACS Sustain. Chem. Eng. 2016, 4, 3948-3959. [CrossRef]

182. Li, S.; Wei, Y.; Kong, Y.; Tao, Y.; Yao, C.; Zhou, R. Electrochemical removal of lead ions using paper electrode of polyaniline/attapulgite composites. Synth. Metals 2015, 199, 45-50. [CrossRef]

183. Kong, Y.; Li, W.; Wang, Z.; Yao, C.; Tao, Y. Electrosorption behavior of copper ions with poly(m-phenylenediamine) paper electrode. Electrochem. Commun. 2013, 26, 59-62. [CrossRef]

184. Yang, S.; Zhang, L.; Yang, Q.; Zhang, Z.; Chen, B.; Lv, P.; Zhu, W.; Wang, G. Graphene aerogel prepared by thermal evaporation of graphene oxide suspension containing sodium bicarbonate. J. Mater. Chem. A 2015, 3, 7950-7958. [CrossRef]

185. Chen, M.; Zhang, C.; Li, X.; Zhang, L.; Ma, Y.; Zhang, L.; Xu, X.; Xia, F.; Wang, W.; Gao, J. A one-step method for reduction and self-assembling of graphene oxide into reduced graphene oxide aerogels. J. Mater. Chem. A 2013, 1, 2869-2877. [CrossRef]

186. Sui, Z.; Meng, Q.; Zhang, X.; Ma, R.; Cao, B. Green synthesis of carbon nanotube-graphene hybrid aerogels and their use as versatile agents for water purification. J. Mater. Chem. 2012, 22, 8767-8771. [CrossRef]

187. Gao, H.; Sun, Y.; Zhou, J.; Xu, R.; Duan, H. Mussel-inspired synthesis of polydopamine-functionalized graphene hydrogel as reusable adsorbents for water purification. ACS Appl. Mater. Interfaces 2013, 5, 425-432. [CrossRef] [PubMed]

188. Zheng, J.; Xia, L.; Song, S. Electrosorption of $\mathrm{Pb}(\mathrm{II})$ in water using graphene oxide-bearing nickel foam as the electrodes. RSC Adv. 2017, 7, 23543-23549. [CrossRef]

189. Ozverdi, A.; Erdem, M. $\mathrm{Cu}^{2+}, \mathrm{Cd}^{2+}$ and $\mathrm{Pb}^{2+}$ adsorption from aqueous solutions by pyrite and synthetic iron sulphide. J. Hazard. Mater. 2006, B137, 626-632. [CrossRef]

190. Kanrar, S.; Debnath, S.; De, P.; Parashar, K.; Pillay, K.; Sasikumar, P.; Ghosh, U.C. Preparation, characterization and evaluation of fluoride adsorption efficiency from water of iron-aluminium oxide-graphene oxide composite material. Chem. Eng. J. 2016, 306, 269-279. [CrossRef]

191. Bai, J.; Sun, H.; Yin, X.; Yin, X.; Wang, S.; Creamer, A.E.; Xu, L.; Qin, Z.; He, F.; Gao, B. Oxygen-content-controllable graphene oxide from electron-beam-irradiated graphite: Synthesis, characterization, and removal of aqueous lead [Pb(II)]. ACS Appl. Mater. Interfaces 2016, 8, 25289-25296. [CrossRef]

192. Li, J.; Zhang, S.; Chen, C.; Zhao, G.; Yang, X.; Li, J.; Wang, X. Removal of Cu(II) and fulvic acid by graphene oxide nanosheets decorated with $\mathrm{Fe}_{3} \mathrm{O}_{4}$ nanoparticles. ACS Appl. Mater. Interfaces 2012, 4, 4991-5000. [CrossRef] [PubMed]

193. Luo, S.; Xu, X.; Zhou, G.; Liu, C.; Tang, Y.; Liu, Y. Amino siloxane oligomer-linked graphene oxide as an efficient adsorbent for removal of $\mathrm{Pb}(\mathrm{II})$ from wastewater. J. Hazard. Mater. 2014, 274, 145-155. [CrossRef] [PubMed]

194. Chakravarty, R.; Banerjee, P.C. Mechanism of cadmium binding on the cell wall of an acidophilic bacterium. Bioresour. Technol. 2012, 108, 176-183. [CrossRef] [PubMed]

195. Deng, S.; Ting, Y.-P. Characterization of PEI-modified biomass and biosorption of $\mathrm{Cu}(\mathrm{II}), \mathrm{Pb}(\mathrm{II})$ and $\mathrm{Ni}(\mathrm{II})$. Water Res. 2005, 39, 2167-2177. [CrossRef] [PubMed]

196. Huang, J.; Ye, M.; Qu, Y.; Chu, L.; Chen, R.; He, Q.; Xu, D. Pb (II) removal from aqueous media by EDTA-modified mesoporous silica SBA-15. J. Colloid Interface Sci. 2012, 385, 137-146. [CrossRef] [PubMed]

197. Xu, Z.; Zhang, Y.; Qian, X.; Shi, J.; Chen, L.; Li, B.; Niu, J.; Liu, L. One step synthesis of polyacrylamide functionalized graphene and its application in $\mathrm{Pb}(\mathrm{II})$ removal. Appl. Surf. Sci. 2014, 316, 308-314. [CrossRef]

198. Villar-Rodil, S.; Paredes, J.I.; Martínez-Alonso, A.; Tascón, J.M.D. Preparation of graphene dispersions and graphene-polymer composites in organic media. J. Mater. Chem. 2009, 19, 3591-3593. [CrossRef]

199. Yang, S.-T.; Chen, S.; Chang, Y.; Cao, A.; Liu, Y.; Wang, H. Removal of methylene blue from aqueous solution by graphene oxide. J. Colloid Interface Sci. 2011, 359, 24-29. [CrossRef]

200. Song, H.; Hao, L.; Tian, Y.; Wan, X.; Zhang, L.; Lv, Y. Stable and water-dispersible graphene nanosheets: Sustainable preparation, functionalization, and high-performance adsorbents for $\mathrm{Pb}^{2+}$. ChemPlusChem 2012, 77. [CrossRef] 
201. Yang, Y.; Xie, Y.; Pang, L.; Li, M.; Song, X.; Wen, J.; Zhao, H. Preparation of reduced graphene oxide/poly(acrylamide) nanocomposite and its adsorption of $\mathrm{Pb}(\mathrm{II})$ and methylene blue. Langmuir 2013, 29, 10727-10736. [CrossRef]

202. Bao, C.; Song, L.; Xing, W.; Yuan, B.; Wilkie, C.A.; Huang, J.; Guo, Y.; Hu, Y. Preparation of graphene by pressurized oxidation and multiplex reduction and its polymer nanocomposites by masterbatch-based melt blending. J. Mater. Chem. 2012, 22, 6088-6096. [CrossRef]

203. Huang, Y.F.; Lin, C.W. Facile synthesis and morphology control of graphene oxide/polyaniline nanocomposites via in-situ polymerization process. Polymer 2012, 53, 2574-2582. [CrossRef]

204. Zhu, J.; Chen, M.; Qu, H.; Zhang, X.; Wei, H.; Luo, Z.; Colorado, H.A.; Wei, S.; Guo, Z. Interfacial polymerized polyaniline/graphite oxide nanocomposites toward electrochemical energy storage. Polymer 2012, 53, 5953-5964. [CrossRef]

205. Liu, Y.; Deng, R.; Wang, Z.; Liu, H. Carboxyl-functionalized graphene oxide-polyaniline composite as a promising supercapacitor material. J. Mater. Chem. 2012, 22, 13619-13624. [CrossRef]

206. Li, X.G.; Feng, H.; Huang, M.R. Strong adsorbability of mercury ions on aniline/sulfoanisidine copolymer nanosorbents. Chem. Eur. J. 2009, 15, 4573-4581. [CrossRef] [PubMed]

207. Kong, Y.; Wei, J.; Wang, Z.; Sun, T.; Yao, C.; Chen, Z. Heavy metals removal from solution by polyaniline/palygorskite composite. J. Appl. Polym. Sci. 2011, 2054-2059. [CrossRef]

208. Lingamdinne, L.P.; Koduru, J.R.; Karri, R.R. A comprehensive review of applications of magnetic graphene oxide based nanocomposites for sustainable water purifiation. J. Environ. Manag. 2019, 231, 622-634. [CrossRef]

209. Lingamdinne, L.P.; Koduru, J.R.; Chang, Y.-Y.; Karri, R.R. Process optimization and adsorption modeling of $\mathrm{Pb}$ (II) on nickel ferrite-reduced graphene oxide nano-composite. J Mol. Liq. 2018, 250, 202-211. [CrossRef]

210. Lingamdinne, L.P.; Choi, Y.-L.; Kim, I.-S.; Chang, Y.-Y.; Koduru, J.R.; Yang, J.-K. Porous graphene oxide based inverse spinel nickel ferrite nanocomposites for the enhanced adsorption removal of arsenic. RSC Adv. 2016, 6, 73776-73789. [CrossRef]

211. Lingamdinne, L.P.; Koduru, J.R.; Choi, Y.-L.; Chang, Y.-Y.; Yang, J.-K. Studies on removal of Pb(II) and Cr(III) using graphene oxide based inverse spinel nickel ferrite nano-composite as sorbent. Hydrometallurgy 2016, 165, 64-72. [CrossRef]

212. Hummers, W.S., Jr.; Offeman, R.E. Preparation of graphitic oxide. J. Am. Chem. Soc. 1958, 80, 1339. [CrossRef]

213. Lingamdinne, L.P.; Kim, I.-S.; Ha, J.-H.; Chang, Y.-Y.; Koduru, J.R.; Yang, J.-K. Enhanced adsorption removal of $\mathrm{Pb}(\mathrm{II})$ and $\mathrm{Cr}(\mathrm{III})$ by using nickel ferrite-reduced graphene oxide nanocomposite. Metals 2017, 7, 225. [CrossRef]

214. Lingamdinne, L.P.; Choi, Y.-L.; Kim, I.-S.; Yang, J.-K.; Koduru, J.R.; Changa, Y.-Y. Preparation and characterization of porous reduced graphene oxide based inverse spinel nickel ferrite nanocomposite for adsorption removal of radionuclides. J. Hazard. Mater. 2017, 326, 145-156. [CrossRef]

215. Wang, D.; Liu, L.; Jiang, X.; Yu, J.; Chen, X.; Chen, X. Adsorbent for p-phenylenediamine adsorption and removal based on graphene oxide functionalized with magnetic cyclodextrin. Appl. Surf. Sci. 2015, 329, 197-205. [CrossRef]

216. Zhu, P.; Liu, S.; Xie, J.; Zhang, S.; Cao, G.; Zhao, X. Facile synthesis of $\mathrm{NiFe}_{2} \mathrm{O}_{4} /$ reduced graphene oxide hybrid with enhanced electrochemical lithium storage performance. J. Mater. Sci. Technol. 2014, 30, 1078-1083. [CrossRef]

217. Shen, J.; Li, X.; Huang, W.; Li, N.; Ye, M. One-pot polyelectrolyte assisted hydrothermal synthesis of $\mathrm{NiFe}_{2} \mathrm{O}_{4}$-reduced graphene oxide nanocomposites with improved electrochemical and photocatalytic properties. J. Mater. Res. 2014, 29, 2211-2219. [CrossRef]

218. Zhang, Y.; Yan, L.; Xu, W.; Guo, X.; Cui, L.; Gao, L.; Wei, Q.; Du, B. Adsorption of Pb(II) and Hg(II) from aqueous solution using magnetic $\mathrm{CoFe}_{2} \mathrm{O}_{4}$-reduced graphene oxide. J. Mol. Liq. 2014, 191, 177-182. [CrossRef]

219. Yao, Y.; Yang, Z.; Zhang, D.; Peng, W.; Sun, H.; Wang, S. Magnetic CoFe2O4-graphene hybrids: Facile synthesis, characterization, and catalytic properties. Ind. Eng. Chem. Res. 2012, 51, 6044-6051. [CrossRef]

220. Guo, S.; Wen, D.; Zhai, Y.; Dong, S.; Wang, E. Platinum nanoparticle ensemble-on-graphene hybrid nanosheet: One-pot, rapid synthesis, and used as new electrode material for electrochemical sensing. ACS Nano 2010, 4, 3959-3968. [CrossRef] 
221. Zhang, F.; Song, Y.; Song, S.; Zhang, R.; Hou, W. Synthesis of magnetite-graphene oxide-layered double hydroxide composites and applications for the removal of $\mathrm{Pb}(\mathrm{II})$ and 2,4-dichlorophenoxyacetic acid from aqueous solutions. ACS Appl. Mater. Interfaces 2015, 7, 7251-7263. [CrossRef]

222. Liu, M.; Chen, C.; Hu, J.; Wu, X.; Wang, X. Synthesis of magnetite/graphene oxide composite and application for cobalt(II) removal. J. Phys. Chem. C 2011, 115, 25234-25240. [CrossRef]

223. Fan, L.; Luo, C.; Sun, M.; Li, X.; Qiu, H. Highly selective adsorption of lead ions by water-dispersible magnetic chitosan/graphene oxide composites. Coll. Surf. B Biointerfaces 2013, 103, 523-529. [CrossRef] [PubMed]

224. Wan, S.; He, F.; Wu, J.; Wan, W.; Gu, Y.; Gao, B. Rapid and highly selective removal of lead from water using graphene oxide-hydrated manganese oxide nanocomposites. J. Hazard. Mater. 2016, 314, 32-40. [CrossRef] [PubMed]

225. Zhang, Q.; Du, Q.; Hua, M.; Jiao, T.; Gao, F.; Pan, B. Sorption enhancement of lead ions from water by surface charged polystyrene-supported nano-zirconium oxide composites. Environ. Sci. Technol. 2013, 47, 6536-6544. [CrossRef] [PubMed]

226. Qin, Q.; Wang, Q.; Fu, D.; Ma, J. An efficient approach for $\mathrm{Pb}(\mathrm{II})$ and $\mathrm{Cd}(\mathrm{II})$ removal using manganese dioxide formed in situ. Chem. Eng. J. 2011, 172, 68-74. [CrossRef]

227. Marcus, Y. Thermodynamics of solvation of ions. Part 5 Gibbs free energy of hydration at 298.15 K. J. Chem. Soc. Faraday Trans. 1991, 87, 2995-2999. [CrossRef]

(C) 2019 by the authors. Licensee MDPI, Basel, Switzerland. This article is an open access article distributed under the terms and conditions of the Creative Commons Attribution (CC BY) license (http://creativecommons.org/licenses/by/4.0/). 